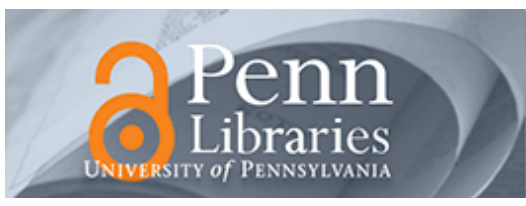

University of Pennsylvania ScholarlyCommons

Wharton Pension Research Council Working

Papers

Wharton Pension Research Council

$6-1-2010$

\title{
Health Cost Risk and Optimal Retirement Provision: A Simple Rule for Annuity Demand
}

Kim Peijnenburg

Tilburg University, j.m.j.peijnenburg@TilburgUniversity.nl

Theo Nijman

Tilburg University, Nyman@TilburgUniversity.nl

Bas JM Werker

Tilburg University, Werker@TilburgUniversity.nl

Follow this and additional works at: https://repository.upenn.edu/prc_papers

Part of the Economics Commons

Peijnenburg, Kim; Nijman, Theo; and Werker, Bas JM, "Health Cost Risk and Optimal Retirement Provision: A Simple Rule for Annuity Demand" (2010). Wharton Pension Research Council Working Papers. 194.

https://repository.upenn.edu/prc_papers/194

This paper is posted at ScholarlyCommons. https://repository.upenn.edu/prc_papers/194

For more information, please contact repository@pobox.upenn.edu. 


\title{
Health Cost Risk and Optimal Retirement Provision: A Simple Rule for Annuity Demand
}

\begin{abstract}
We analyze the effect of health cost risk on optimal annuity demand and consumption/savings decisions. Many retirees are exposed to sizeable out-of-pocket medical expenses, while annuities potentially impair the ability to get liquidity to cover these costs and smooth consumption. We find that if out-of-pocket medical expenses can already be sizeable early in retirement, full annuitization is not optimal. In the other case of low health cost risk early in retirement, individuals should take advantage of the mortality credit that annuities provide and save out of the annuity income to build a buffer for health cost shocks at later ages. When comparing to empirically observed levels of annuitization, we find that high health cost risk early in retirement may resolve the annuity puzzle. Moreover, we explain the observed pattern of annuitization as a function of initial wealth at retirement. For personal financial planning purposes, we develop a simple rule of thumb for annuity demand, based on expected health cost risk early in retirement, wealth at retirement, and minimum consumption levels. We show that the welfare costs from using the rule compared to the full life cycle model are small.
\end{abstract}

\section{Keywords}

Optimal life cycle portfolio choice, health cost risk, annuity, retirement

\section{Disciplines}

Economics 


\title{
Health Cost Risk and Optimal Retirement Provision: A Simple Rule for Annuity Demand
}

\author{
Kim Peijnenburg, Theo Nijman, and Bas J.M. Werker
}

June 2010

\author{
PRC WP2010-08 \\ Pension Research Council Working Paper \\ Pension Research Council \\ The Wharton School, University of Pennsylvania \\ 3620 Locust Walk, 3000 SH-DH \\ Philadelphia, PA 19104-6302
}

Tel: 215.898.7620 Fax: 215.573.3418

Email: prc@wharton.upenn.edu

http://www.pensionresearchcouncil.org

Opinions and conclusions are solely those of the author(s) and do not reflect views of the institutions supporting the research, with whom the authors are affiliated, or the Pension Research Council. Copyright 2010 (C) Pension Research Council of the Wharton School of the University of Pennsylvania. All rights reserved. 


\title{
Health Cost Risk and Optimal Retirement Provision: A Simple Rule for Annuity Demand
}

\author{
Kim Peijnenburg, Theo Nijman, and Bas J.M. Werker
}

\begin{abstract}
We analyze the effect of health cost risk on optimal annuity demand and consumption/savings decisions. Many retirees are exposed to sizeable out-of-pocket medical expenses, while annuities potentially impair the ability to get liquidity to cover these costs and smooth consumption. We find that if out-of-pocket medical expenses can already be sizeable early in retirement, full annuitization is not optimal. In the other case of low health cost risk early in retirement, individuals should take advantage of the mortality credit that annuities provide and save out of the annuity income to build a buffer for health cost shocks at later ages. When comparing to empirically observed levels of annuitization, we find that high health cost risk early in retirement may resolve the annuity puzzle. Moreover, we explain the observed pattern of annuitization as a function of initial wealth at retirement. For personal financial planning purposes, we develop a simple rule of thumb for annuity demand, based on expected health cost risk early in retirement, wealth at retirement, and minimum consumption levels. We show that the welfare costs from using the rule compared to the full life cycle model are small.
\end{abstract}




\title{
Health Cost Risk and Optimal Retirement Provision: A Simple Rule for Annuity Demand*
}

\author{
Kim Peijnenburg $^{\dagger} \quad$ Theo Nijman $^{\ddagger} \quad$ Bas J.M. Werker $^{\S}$
}

May 23, 2010

\begin{abstract}
We analyze the effect of health cost risk on optimal annuity demand and consumption/savings decisions. Many retirees are exposed to sizeable out-of-pocket medical expenses, while annuities potentially impair the ability to get liquidity to cover these costs and smooth consumption. We find that if out-of-pocket medical expenses can already be sizeable early in retirement, full annuitization is not optimal. In the other case of low health cost risk early in retirement, individuals should take advantage of the mortality credit that annuities provide and save out of the annuity income to build a buffer for health cost shocks at later ages. When comparing to empirically observed levels of annuitization, we find that high health cost risk early in retirement may resolve the annuity puzzle. Moreover, we explain the observed pattern of annuitization as a function of initial wealth at retirement. For personal financial planning purposes, we develop a simple rule of thumb for annuity demand, based on expected health cost risk early in retirement, wealth at retirement, and minimum consumption levels. We show that the welfare costs from using the rule compared to the full life cycle model are small.
\end{abstract}

Keywords: Optimal life cycle portfolio choice, health cost risk, annuity, retirement JEL classification: D14, D91, G11, I1

\footnotetext{
${ }^{*}$ We thank Katie Carman, Norma Coe, Donna Gilleskie, Thijs van der Heijden, David Hollanders, John Bailey Jones, Ralph Koijen, David Love, Ronald Mahieu, Roel Mehlkopf, Olivia Mitchell, Lisanne Sanders, Kent Smetters, Ralph Stevens, Annie Yang, and seminar participants at the University at Albany, University of North Carolina, Tilburg University, The Wharton School, and the Netspar Pension Day for helpful comments and suggestions. Part of this research was conducted while Kim Peijnenburg was visiting the Wharton School of the University of Pennsylvania, and she gratefully acknowledges their hospitality. We acknowledge financial support by All Pensions Group (APG). We thank Eric French for sharing the parameter estimates from De Nardi, French, and Jones (2010a) and Stijn van Nieuwerburgh for sharing the estimates from Ameriks, Caplin, Laufer, and Van Nieuwerburgh (2009). The most recent version of this paper is available at www.kimpeijnenburg.com

${ }^{\dagger}$ Finance and Econometrics Group, CentER, Tilburg University and Netspar, Tilburg, the Netherlands, 5000 LE. Phone: 31-134663028. Email: j.m.j.peijnenburg@TilburgUniversity.nl.

${ }^{\ddagger}$ Finance and Econometrics Group, CentER, Tilburg University and Netspar, Tilburg, the Netherlands, 5000 LE. Phone: 31-134662342. Email: Nyman@ TilburgUniversity.nl.

${ }^{\S}$ Finance and Econometrics Group, CentER, Tilburg University and Netspar, Tilburg, the Netherlands, 5000 LE. Phone: 31-134662532. Email: Werker@ TilburgUniversity.nl.
} 


\section{Introduction}

As a consequence of an ageing population in developed countries, much attention (both by policymakers and academics) is directed towards providing and optimizing financial security during retirement. In this respect, the most important risks the elderly face are health cost risk and longevity risk. People can outlive their assets and can also be confronted with high out-of-pocket medical expenses. These health costs have increased substantially over the last decades, in all Western countries. At the same time the variation in health costs (thus health risk) increased as well. The main goal of pension policies, and social security in general, is to provide financial security to individuals. Thus health risk, as one of the major financial risks for the elderly, should be taken into account when designing such a system. In spite of health risks being actively discussed in the public policy debate, few papers examine what spending policy is optimal when retirees face health risk. In this paper we attempt to fill this gap and examine to what extent individuals can still annuitize their wealth when facing health risk, to obtain an optimal trade-off between longevity risk insurance and saving for unexpected liquidity needs due to health costs. From a positive perspective, we explore whether out-of-pocket medical expenses can explain empirically observed annuitization levels.

Prior research has shown that full annuitization is optimal for individuals who only face uncertainty about their time of death. Yaari (1965) showed that risk averse agents with no desire to leave a bequest find it optimal to hold their entire wealth in actuarially fair annuities, when longevity is the only risk factor. However, in fact a relatively small amount of individuals voluntarily purchases annuity products when they reach retirement age. In order to reconcile this result with the empirical findings, a vast amount of literature has focussed on this "annuity puzzle". Mitchell, Poterba, Warshawsky, and Brown (1999) examine actuarially unfair annuities as a potential driver of deviation from full annuitization, and Inkmann, Lopes, and Michaelides (2008) and Lockwood (2010) look at bequest motives. We abstract from bequest motives, because the evidence on the strength of bequest motives is mixed (Brown (2001), De Nardi (2004), and Kopczuk and Lupton (2007)). In addition, some papers explore the effect on annuity demand of incomplete annuity markets (Peijnenburg, Nijman, and Werker (2010)), default risk (Babbel and Merril (2006)), meanstested benefits (Bütler, Peijnenburg, and Staubli (2009)), systematic longevity risk (Stevens (2009)), and family composition (Kotlikoff and Spivak (1981)). Furthermore, several behavioral explanations have been posited, such as framing of the annuity choice (Brown, Kling, Mullainathan, and Wrobel (2008), Gazzale and Walker (2009)) and mental accounting (Brown (2007) and Hu and Scott (2007)).

More closely related to our paper, Chai, Horneff, Maurer, and Mitchell (2009), Feinstein and Lin (2006), Hugonnier, Pelgrin, and St-Amour (2009), Love and Perozek (2007), Poterba, Venti, and Wise (2010), and Turra and Mitchell (2008) show the effect of health cost risk on portfolio choice, while Berkowitz and Qiu (2006) and Smith and Love (2007) focus on the influence of health status on portfolio allocation decisions. Furthermore there are several papers that examine the relation between health risk and retirement timing (Bound, Stinebrickner, and Waidmann (2010) and French (2005)). Fonseca, Michaud, Galama, and Kapteyn (2009) try to explain the rise in health cost over the past decades. Several recent papers (De Nardi, French, and Jones (2010b) and Kopecky and Koreshkova (2009)) analyze changes in savings behavior due to policy reforms that alter out-of-pocket medical expenditures. In this paper we expand on the previous literature by examining the effect of uninsured health costs on annuity demand and savings. 
We build a life cycle model for consumption and portfolio choice to examine the effect of health cost risk on annuity demand. That is, out-of-pocket medical expenses raise the need for liquidity and hence give incentives for precautionary saving ( De Nardi, French, and Jones (2010a), Dynan, Skinner, and Zeldes (2004), and Palumbo (1999)). As a consequence, uncertain medical costs can reduce the attractiveness of annuities since they impair the ability to smooth consumption in case of high and unexpected health costs. In our model, retirees optimally choose the fraction of wealth annuitized at retirement and follow optimal consumption and asset allocation strategies afterwards, facing capital markets risk and inflation risk. In the literature, a variety of health cost models are proposed. We use out-of-pocket medical costs from four prominent models for health costs and find that optimal annuity demand decreases if health costs can already be high early in retirement. If not, agents can save out of their annuity income to build a sufficient buffer against unexpected medical expenses at later ages. To what extent full annuitization is optimal thus depends critically on the specific assumption about health costs in early retirement years. We develop a rule of thumb to determine optimal annuity demand, which is easy to use for personal financial planning. The welfare costs from using this simple rule are small.

This paper contributes to the household economics literature in three ways. Our first contribution is that we find that the optimal annuity demand depends crucially on the health cost risk early in retirement. The amount of health costs after about 5 years after the annuitization decision is mostly irrelevant for the optimal annuity demand. In case the health cost risk is moderate early in retirement, it is optimal for agents to annuitize all wealth and save out of the annuity income to build a sufficient buffer for high out-of-pocket medical expenses later in retirement. If, on the other hand, out-of-pocket expenses can be high early in retirement, agents keep a certain amount of wealth liquid, because they do not have enough time to build a buffer to be able to smooth consumption in case of a health cost shock. We explore this by examining the optimal annuity demand for different specifications of health costs estimated in the following papers: Ameriks, Caplin, Laufer, and Van Nieuwerburgh (2009), De Nardi, French, and Jones (2010a), French and Jones (2004), and Scholz, Seshadri, and Khitatrakun (2006). The paper by Ameriks, Caplin, Laufer, and Van Nieuwerburgh (2009) examines a similar question as we do, while the other papers focus either on precautionary savings due to health expenses or mainly on estimating out-of-pocket expenditures. As far as the question raised in our paper is concerned, Ameriks, Caplin, Laufer, and Van Nieuwerburgh (2009) calculate the willingness to pay for an annuity which increases the fraction annuitized from 55\% to $70 \%$ for a fairly wealthy female. We expand on Ameriks, Caplin, Laufer, and Van Nieuwerburgh (2009) by determining the optimal annuity levels and do this for heterogenous investors, which is particularly important since the empirically observed annuity levels vary sizeably depending on the wealth levels.

Furthermore we compare the empirically observed annuitization levels with the optimal annuity demand for a range of wealth levels. We find that if health cost risk is indeed sizeable early in retirement, this can explain the annuity puzzle. The optimal annuity demand is lower than the empirically found annuity levels, not only when aggregating all wealth levels, but for the entire range of wealth levels. In reality agents with low wealth have higher annuitization levels than wealthier retirees. We find the exact same pattern in optimal annuitization levels. So in contrast to the previous literature, we not only propose a conceivable solution for the annuity puzzle, but find that the empirically established annuity pattern is close to the optimal pattern 
when agents face high health cost risk early in retirement.

Our third contribution is that we develop a rule of thumb for the optimal annuity demand with health cost risk. This is useful, both to get a better intuition about the main drivers of optimal annuity demand, but also for personal financial planning purposes. As Baby Boomers approach retirement, this generation may turn to financial service providers for advice on how to manage their retirement assets. As such, a simple heuristic for the optimal annuity demand is especially advantageous. If agents think there is a likely probability to have high health shocks already early in retirement it is optimal for them to reduce annuity demand. We derive a rule of thumb based on a simple stylized model and find that the welfare costs from using this simple rule compared to the full life cycle model are small, for all health cost models. A key input to our rule of thumb is the agent's subjective assessment of the amount of health cost risk in the first years after retirement.

Health costs can be viewed in two different ways: either they are exogenous or endogenous. ${ }^{1}$ We assume they are exogenous. Of course, part of out-of-pocket medical expenses may be a choice, hence health costs are overstated to a certain degree. Yogo (2009) examines the optimal allocation to health care and financial assets, and assumes (fully) endogenous investments in health capital. He finds that medical expenses can partly explain the annuity puzzle. This model setup, however, implies that agents can influence their health status and survival probabilities by increasing their health expenditures. This is contradicted in many empirical studies that find, at most, weak evidence that higher health care utilization leads to an increase in survival probabilities (see for instance Brook et al. (1983) or Finkelstein and McKnight (2008)).

The remainder of the paper is organized as follows. Section 2 describes the life cycle model during the retirement phase. In Section 3, we present the four health cost models that we use to determine and compare optimal annuity demand. The main findings are given in Section 4 and the rule of thumb for the optimal annuity demand is addressed in Section 5. Section 6 concludes.

\section{The retirement phase life cycle model}

\subsection{An individual's maximization problem}

We restrict our analysis to individuals during retirement. ${ }^{2}$ We consider a life cycle investor of age $t \in$ $1, \ldots, T$, where $t=1$ is the retirement date and $T$ is the maximum age possible. Individuals maximize utility over real consumption and preferences are represented by a time-separable, constant relative risk

\footnotetext{
${ }^{1}$ Furthermore, we assume implicitly that health costs are (partly) uninsurable. If a perfect market for health cost insurance would exist, then it is optimal for an agent to buy insurance which fully covers medical costs. However since the market for private care insurance fails to a certain degree, we take as a given that health care costs are only partially insured. See Brown and Finkelstein (2007) for an analysis of the supply-side and demand-side factors for the lack of private insurance against long term care costs.

${ }^{2}$ In Horneff, Maurer, Mitchell, and Stamos (2009) and Maurer, Mitchell, and Rogalla (2010) the pre-retirement period is included in the life-cycle model, but for our application this has no significant added value.
} 
aversion expected utility function over real consumption $\left(C_{t}\right)$. Lifetime utility is then

$$
\begin{aligned}
V & =E_{0}\left[\sum_{t=1}^{T} \beta^{t-1}\left(\prod_{s=1}^{t} p_{s}\right) u\left(C_{t}\right)\right], \text { with } \\
u\left(C_{t}\right) & =\frac{C_{t}^{1-\gamma}}{1-\gamma}
\end{aligned}
$$

where $\beta$ is the time preference discount factor, $\gamma$ the level of risk aversion, and $C_{t}$ is the real amount of wealth consumed at the beginning of period $t$. The probability of surviving to age $t$, conditional on having lived to period $t-1$, is indicated by $p_{t}$. We denote nominal consumption as $\overline{C_{t}}=C_{t} \Pi_{t}$, where $\Pi_{t}$ is the price index at time $t$. In this specification the marginal utility is not dependent on the health status, however as a robustness test we consider a decline in marginal utility when an agent is in a bad health status. Furthermore we use a unitary framework, the utility specification is for an individual, not a household. ${ }^{3}$

The fraction, $w_{t}$, invested in equity is chosen optimally, which yields a gross nominal return $R_{t+1}$ in year $t+1$. The remainder of liquid wealth is invested in a riskless bond with return $R_{t}^{f}$. Next period's wealth, in nominal terms, is thus given by

$$
W_{t+1}=\left(W_{t}+Y_{t}-H_{t}-\overline{C_{t}}\right)\left(1+R_{t}^{f}+\left(R_{t+1}-R_{t}^{f}\right) w_{t}\right),
$$

where $W_{t}$ is the amount of financial wealth at time $t, Y_{t}$ is the annual nominal annuity income, and out-ofpocket health costs are indicated by $H_{t}$. The timing of decisions is as follows. First the individual receives his annuity income and pays health costs. After this exogenous shock, the agent decides how much to consume and subsequently invests remaining liquid wealth, choosing optimally the equity exposure $w_{t}$. In case the annuity income plus wealth at the beginning of the period is insufficient to pay for health expenses and consumption, the individual receives a low minimum consumption level, $C_{\min }$. The decision frequency is annually.

Consumption and asset allocation are chosen optimally subject to a number of constraints. First, we assume that the retiree faces borrowing and short-sales constraints

$$
w_{t} \geq 0 \text { and } 1 \leq w_{t}
$$

Second, we make the standard assumption that the investor is liquidity constrained

$$
\overline{C_{t}} \leq W_{t}
$$

which implies that the individual cannot borrow against future annuity income to increase consumption today.

\footnotetext{
${ }^{3}$ Bourguignon, Browning, and Chiappori (2009) and Cherchye, De Rock, and Vermeulen (2010) present a utility framework for the household.
} 


\subsection{Financial markets}

We assume that the asset menu of an investor consists of two assets: a riskless one-year nominal bond and a risky stock. The return on the stock is lognormally distributed with an annual mean nominal return $\mu_{R}$ and a standard deviation $\sigma_{R}$. We assume the nominal interest rate is generated by a Vasicek model, to account for long term mean reversion. The real yield is equal to the nominal yield minus expected inflation and an inflation risk premium.

In our market, the instantaneous expected inflation rate follows:

$$
d \pi_{t}=-\alpha_{\pi}\left(\pi_{t}-\mu_{\pi}\right) d t+\sigma_{\pi} d Z_{t}^{(\pi)}
$$

where $\alpha_{\pi}$ is the associated mean reversion parameter, $\mu_{\pi}$ is long run expected inflation, $\sigma_{\pi}$ is the standard deviation of shocks to expected inflation, and $d Z_{t}^{(\pi)}$ denotes a Brownian shock. Subsequently, the price index $\Pi$ follows from

$$
\Pi_{t+d t}=\Pi_{t} \exp \left(\pi_{t+d t}+\sigma_{\Pi} d Z_{t}^{(\Pi)}\right)
$$

where $d Z_{t}^{(\Pi)}$ are the innovations to the price index. We assume there is a positive relation between the expected inflation and the instantaneous short interest rate: $\operatorname{cor}\left(d Z_{t}^{(r)}, d Z_{t}^{(\pi)}\right)>0$. The parameters we use are described in Section 2.3.

We consider single-premium immediate life-contingent annuities with real payouts. Consequently, the annuity income is given by

$$
Y=P_{0} A^{-1}
$$

where $P_{0}$ is the premium and $A$ the annuity factor. The single premium is equal to the present value of expected benefits paid to the annuitant and we assume an actuarially fair annuity. The annuity factor, $A$, is thus equal to

$$
A=\sum_{t=1}^{T} \exp \left(-t R_{0}^{(t)}\right) \prod_{s=1}^{t} p_{s},
$$

where $R_{0}^{(t)}$ is the real time zero yield on a zero coupon bond maturing at time $t$. The survival probabilities applied to calculate the annuity factor are unconditional on the health status, but conditional on gender. The survival probabilities $p_{t}$ are generated via the health cost models, and we assume a certain death by age 100 . The method we use to solve our life cycle problem is described in Appendix A

\subsection{Parameter values}

We do not estimate the parameters ourselves, but employ common parameters used within the life cycle literature. As in Pang and Warshawsky (2010) and Yogo (2009), we set $\beta$, the time preference discount factor, equal to 0.96 . The risk aversion coefficient $\gamma$ is 5 , which is consistent with previous studies. We determine the optimal annuity demand for a range of initial total wealth levels, and to illustrate the consumption and savings decisions the wealth level is equal to $\$ 350,000$. This is approximately equal to the average total wealth level for a single person U.S. household (Dushi and Webb (2004)). The minimum consumption level 
guaranteed by the government is set equal to $\$ 7000$ annually. Ameriks, Caplin, Laufer, and Van Nieuwerburgh (2009) note that the payments under the government's Supplemental Security Income are about $\$ 7000$ per year and they estimate the consumption floor to be $\$ 5700$.

The equity return is assumed to be lognormally distributed and in accordance with historical stock returns we assume a mean annual nominal return of $8 \%$ and an annual standard deviation of $20 \%$. The mean instantaneous short rate is set equal to $4 \%$, the standard deviation to $1 \%$, and the mean reversion parameter to 0.15 . The inflation risk premium to determine the real yield is $0.5 \%$. The correlation between the instantaneous short rate and the expected inflation is 0.4. Mean inflation is equal to $2 \%$, and the standard deviation of the instantaneous inflation rate is equal to $1.3 \%$, the standard deviation of the price index equals $1.3 \%$, and the mean reversion coefficient equals 0.15 . Time ranges from $t=1$ to time $T$, which corresponds to age 65 and 100 respectively.

\section{Health cost models for out-of-pocket expenditures}

A large part of U.S. health costs is paid out-of-pocket. Brown and Finkelstein (2009) note that for the health sector as a whole $17 \%$ is paid out-of-pocket, and one-third of long term care costs. The costs for nursing homes amount to $\$ 50,000$ per year for a semi-private room and Brown and Finkelstein (2008) estimate that about one-third of current 65-year olds will enter a nursing home at some point in time. Insurance policies for long term care do exist, but the contract typically purchased covers only $34 \%$ of the expected present discounted value of long-term care costs (Brown and Finkelstein (2007)). For this reason, health cost risk is one of the most important risks that elderly face today.

\subsection{Exogenous versus endogenous health costs}

Out-of-pocket medical expenses can be viewed in two ways, exogenous or endogenous. Yogo (2009) assumes that retirees can endogenously invest in health care and build up health capital. Health depreciates at a stochastic rate and agents choose the amount of health expenditures after a depreciation. This does require the acceptance of the hypothesis that individuals can influence their health status and survival probabilities by spending more on health care. Empirical evidence shows that there is a negligible impact of health care utilization on survival probabilities. Finkelstein and McKnight (2008) find that the introduction of Medicare in 1965 had no significant impact on the mortality of elderly people. This finding is further supported by Brook et al. (1983) who find that there is at most a minimal influence of increased health care usage on subsequent health. This paper uses the RAND Health Insurance Experiment; agents were randomly assigned to either the control group with standard co-payments, or to get a co-payment free health insurance for three to five years. They find that even though the individuals who did not face co-payments utilized care more, this additional health care had at most a minor impact on health outcomes. For this reason we assume that out-of-pocket medical expenses are exogenous. 


\subsection{Specification of the health cost models}

Several papers in the literature estimate out-of-pocket medical expenses, though the dynamics for health cost risk differs substantially. For this reason we take the estimates for the process of health expenses from four prominent papers in the literature and determine the optimal annuity demand. In this manner we can, as a first step, disentangle what characteristics of health costs are the main determinant of optimal annuity demand, which is the primary focus of this paper. Furthermore, we explore which assumptions about health costs can explain the annuity puzzle.

We examine four different models for health costs: (1) De Nardi, French, and Jones (2010a), (2) Ameriks, Caplin, Laufer, and Van Nieuwerburgh (2009), (3) Scholz, Seshadri, and Khitatrakun (2006), and (4) French and Jones (2004). The models vary according to how they specify the stochastic process for health costs and the dataset and/or period employed.

(1) De Nardi, French, and Jones (2010a):

De Nardi, French, and Jones (2010a) document that there exists substantial heterogeneity in out-of-pocket health expenses among individuals, by gender, health status, age, and permanent income. They use data from 1994 to 2006 of the Assets and Health Dynamics of the Oldest Old (AHEAD) dataset, which is a part of the Health and Retirement Study (HRS). The individuals who are in the AHEAD dataset in 1994 are 70 years or older and non-institutionalized, which thus presents a relatively healthy subsample of the population and health costs early in retirement are likely to be underestimated. Health costs are the sum of what individuals spend out-of-pocket on insurance premia, drug costs, costs for hospital, nursing home care, doctor visits, dental visits, and outpatient care. Individuals face three sources of risk, which they treat as exogenous:

- Health status uncertainty. A person can be in a good or bad health status. The transition probabilities between health states depend on the previous health status $(\mathrm{h})$, gender $(\mathrm{g})$, permanent income (I), and age (a).

- Survival uncertainty. The probability that a person is alive the next period depends on his health status, permanent income, age, and gender.

- Medical expense uncertainty. Health costs depend on gender, health status, permanent income, age, and an idiosyncratic component, $\psi_{t}$.

Both the mean and the variance of the log medical expenses depend on gender, health status, permanent income, and age:

$$
\ln m_{t}=m(g, h, I, a)+\sigma(g, h, I, a) \psi_{t} .
$$

where $\psi_{t}$ can be decomposed as

$$
\begin{aligned}
\psi_{t} & =\varsigma_{t}+\xi_{t}, \quad \xi_{t} \sim N\left(0, \sigma_{\xi}^{2}\right), \\
\varsigma_{t} & =\rho_{m} \varsigma_{t-1}+\varepsilon_{t}, \quad \varepsilon_{t} \sim N\left(0, \sigma_{\varepsilon}^{2}\right) .
\end{aligned}
$$

where $\xi_{t}$ and $\varepsilon_{t}$ are serially and mutually independent. The setup allows for empirically observed autocor- 
relation patterns in expenses. ${ }^{4}$

A key feature of this model is that health costs and survival probabilities are negatively correlated. Both the medical expenditures and survival probabilities depend on the health status of the agent. So in case the agent is in a bad health status, his expected medical expenses are higher and his life expectancy is lower. This is particularly important when examining the effect of health costs on annuity demand. Namely the negative correlation between survival probabilities and life expectancy can make annuities relatively more attractive, because after having incurred large health expenses, the agent is more likely to die, which makes the depletion of wealth due to the medical expenses less costly in utility terms. ${ }^{5}$

\section{(2) Ameriks, Caplin, Laufer, and Van Nieuwerburgh (2009):}

Ameriks, Caplin, Laufer, and Van Nieuwerburgh (2009) model four health states: (1) good health, (2) medical problems but no long term care, (3) long term care, and (4) death. They assume the health status follows a Markov chain with an age-varying one-period state transition matrix. The values for the parameters for the transition matrix are set to match four age-dependent mortality rates and eight statistics on long term care utilization taken from Brown and Finkelstein (2008). Each state when the agent is alive is associated with a necessary and deterministic health cost. The health costs if the agent is in good health status (1) is $\$ 1000$, in the intermediate health status (2) the associated costs are $\$ 10,000$, and if the agent is in need of long term care (3) the annual costs are $\$ 50,000 .{ }^{6}$

\section{(3) Scholz, Seshadri, and Khitatrakun (2006):}

Scholz, Seshadri, and Khitatrakun (2006) use the HRS dataset from 1992 to 2004 to estimate out-of-pocket medical expenses. The specification for health costs for retired agents is given by:

$$
\begin{gathered}
\ln m_{t}=\beta_{0}+\beta_{1} a_{t}+\beta_{2} a_{t}^{2}+u_{t}, \\
u_{t}=\rho u_{t-1}+\epsilon_{t}, \quad \epsilon_{t} \sim N\left(0, \sigma_{\epsilon}^{2}\right)
\end{gathered}
$$

where $a_{t}$ is the age of the individual, $u_{t}$ is the $\operatorname{AR}(1)$ error term, and $\epsilon_{t}$ is white noise. They estimate this specification for singles with a college degree and without a college degree, and for households with and without a college degree. We use the estimates for singles, since our utility specification is for a single household.

\section{(4) French and Jones (2004):}

French and Jones (2004) use the HRS and AHEAD dataset to estimate out-of-pocket medical expenses. The

\footnotetext{
${ }^{4}$ De Nardi, French, and Jones (2010a) estimate their model using data on elderly of 70 years and older, while our model ranges from age 65 to 100 . We extrapolate their results to find health status transition probabilities, survival probabilities, and medical expenses between age 65 and 69. Specifically, we estimate health status transition probabilities with a third order polynomial in age, medical expenses with a first order polynomial in age, and we apply the survival probabilities at age 70 to ages 65 to 69 .

${ }^{5}$ A negative correlation between health costs and survival probabilities can also decrease annuity demand. Sinclair and Smetters (2004) find that when agents can resell their annuity, annuity demand decreases due to health risk. The present value of the annuity decreases just as the need for liquidity increases. Hence at the moment the agent wants to sell his annuity to get liquidity, the value of the annuity has decreased. In our paper we assume agents cannot resell their annuities, because there is almost no market for this, since the adverse selection costs are extremely large.

${ }^{6}$ The deterministic health costs in the first two states are calibrated in such a way to match estimates in French and Jones (2004) with the health status transition matrix. To determine the health costs in the long term care health status, they use Metlife's estimates for costs for a semi-private room in a LTC facility. The costs are $\$ 143$ per day and medicare covered the full cost of LTC for 20 days each year and the daily costs in excess of $\$ 109.50$ for an additional 80 days. This amounts to a total of $\$ 46,700$ for a year of long term care for an agent without long term care insurance.
} 
AHEAD waves used are from 1993, 1995, 1998, and 2000 and from the HRS dataset the 1994, 1996, 1998, and 2000 waves. They find that their data is well represented by an AR(1) process:

$$
\begin{array}{r}
\ln m_{t}=X_{t} \beta+R_{t} \\
R_{t}=a_{t}+u_{t} \\
a_{t}=\rho a_{t-1}+\epsilon_{t}
\end{array}
$$

where $X_{t}$ includes gender, marital status, age, age ${ }^{2}, \log$ income, and several indicators about whether or what type of insurance the agent has.

\subsection{Dynamics and distribution of the health costs}

Figure 1 displays the mean and quantiles of medical expenses for the four specifications. The health costs of De Nardi, French, and Jones (2010a) and French and Jones (2004) are available both for males and females, while for Ameriks, Caplin, Laufer, and Van Nieuwerburgh (2009) and Scholz, Seshadri, and Khitatrakun (2006) the out-of-pocket medical expenditures are not separately estimated for males and females. The annual health costs according to the model by Scholz, Seshadri, and Khitatrakun (2006) can get extremely large in the tails, because the model fits the mean of the log health costs well, but not the tail. ${ }^{7}$ For this reason we exclude the highest $1 \%$ health costs from our simulations.

Most importantly, we see that the pattern of health costs over the life cycle differs substantially between the four models, as well as the amount of health costs over the entire life. Panel 1a shows the mean, and we see that the health costs from the De Nardi et al. (2009) model increases substantially with age. This pattern also holds for the three quantiles that are displayed in the other figures. The shape of the quantiles of health costs over the life cycle varies largely. The health costs according to Scholz et al. (2006) display a hump-shaped form, which is not the case for the model by Ameriks et al. (2009). The reason is that the health costs in the model by Ameriks et al. (2006) can only take on the values $\$ 1000, \$ 10,000$, and $\$ 50,000$. Hence the $5 \%$ highest health costs (panel $1 \mathrm{~b}$ ) are equal to exactly $\$ 50,000$, for most ages. Finally, we see that the health costs, according to the model by French and Jones (2004), increases linearly with age.

For ease of exposition we label the four health cost models according to the shape of their 99th percentile of health costs over the life cycle. We choose this percentile, because in Section 4.2 we show that the tail of the health costs, in particular in the first years after retirement, is important for determining the optimal annuity demand. We label the four models as follows:

- Exponential health costs = De Nardi, French, and Jones (2010a)

- Piecewise constant health costs = Ameriks, Caplin, Laufer, and Van Nieuwerburgh (2009)

- Hump-shaped health costs = Scholz, Seshadri, and Khitatrakun (2006)

- Linear health costs = French and Jones (2004)

\footnotetext{
${ }^{7} 1$ in a 1000 individuals incurs health costs of about 20 million at a given year after age 75 .
} 


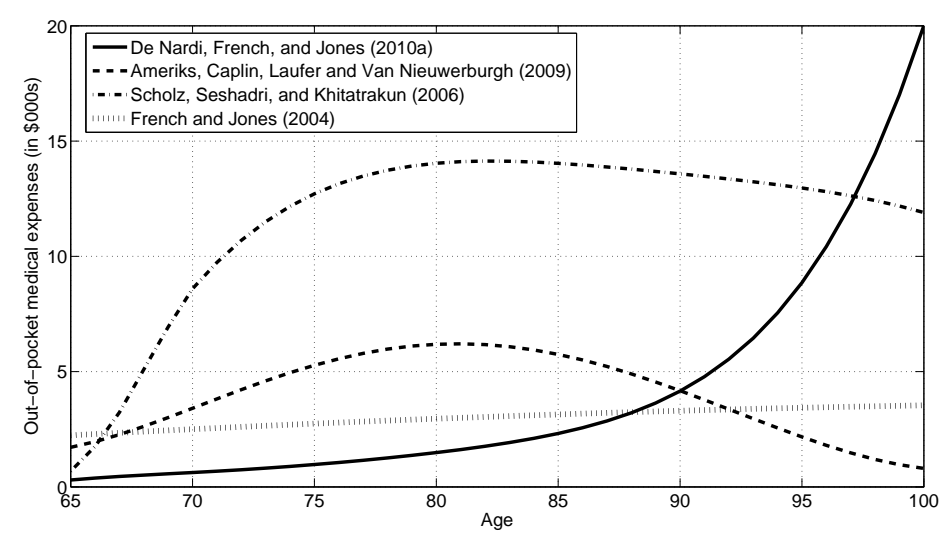

(a) Mean

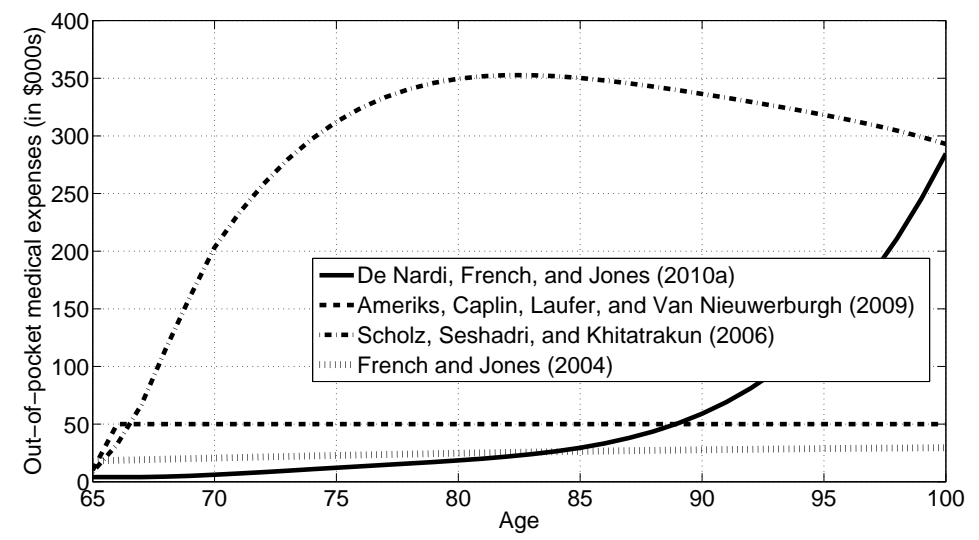

(c) 99th percentile

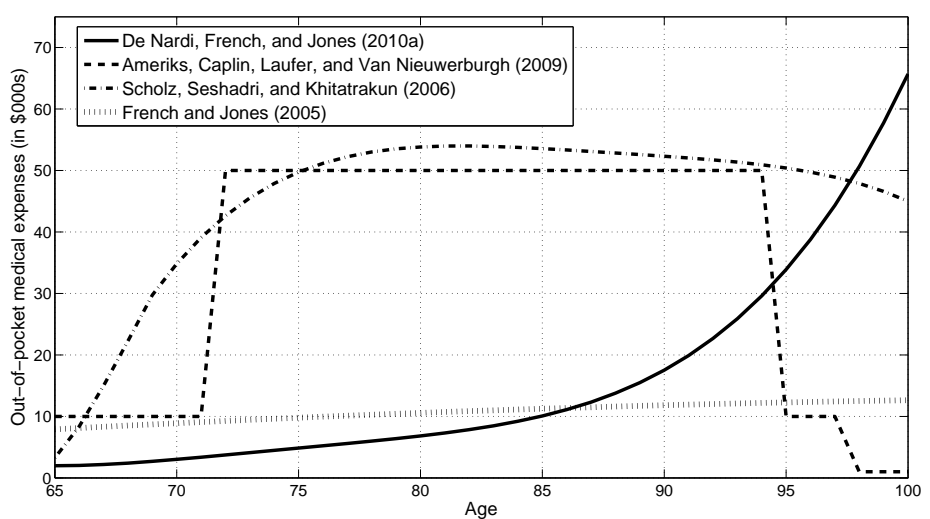

(b) 95 th percentile

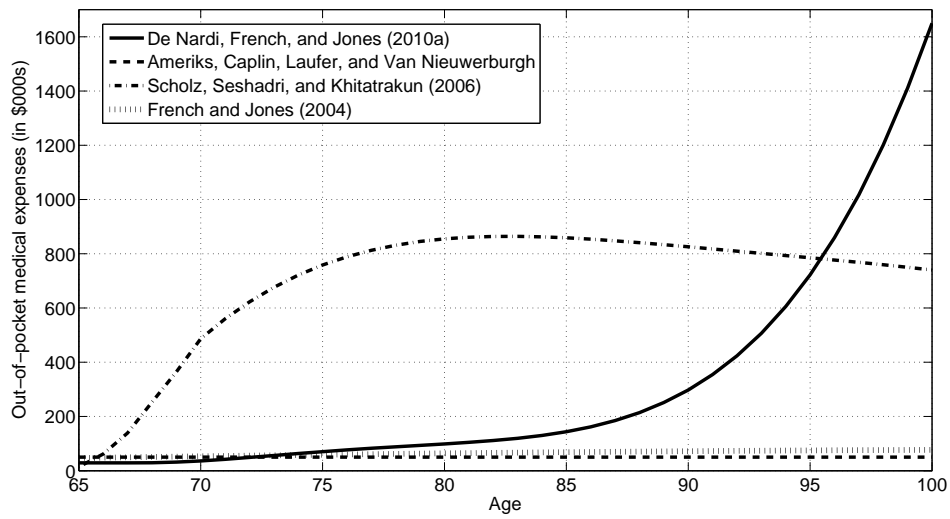

(d) 99.9th percentile

Figure 1: Simulated annual out-of-pocket health costs from age 65 to 100

This graph displays the mean, the 95th, 99th, and 99.9th percentile of health costs, for four models. The health costs for De Nardi, French, and Jones (2010a) and French and Jones (2004) are for females. The health costs for the other two models is combined for males and females. Note that in these graphs the top 1\% is already excluded of the simulations following Scholz, Seshadri, and Khitatrakun (2006). 


\section{Optimal annuity demand and health cost risk}

Full annuitization is optimal in a world where individuals only face longevity risk (Yaari (1965)). However, this result might no longer hold if individuals face substantial health risk which raises liquidity needs. In Section 4.1 we focus on the optimal annuity demand and savings decision when agents face exponential health costs. We first examine the exponential model, because this model includes gender as a factor to explain health costs, which allows us to identify the optimal annuity demand for both males and females. ${ }^{8}$ In this way we can illustrate in detail the effect of out-of-pocket medical expenses on savings and consumption. In the subsequent section, we determine the optimal annuity demand for the four health cost models, and for various wealth levels and minimum consumption levels.

\subsection{Optimal annuity demand and savings with exponential health costs}

Note that in this section we determine the optimal annuity demand and savings and consumption decisions for an agent who faces exponential health costs. In Section 4.2 we examine optimal annuitization levels for other health cost models and various wealth levels. In Figure 2 we present (for our benchmark specification) the certainty equivalent consumption for various annuitization levels, adopting optimal consumption and asset allocation strategies. The dashed line presents the case for a female who does not face out-ofpocket medical expenses. Not surprisingly we find that full annuitization is optimal, which is in accordance with Mitchell, Poterba, Warshawsky, and Brown (1999) and Peijnenburg, Nijman, and Werker (2010). The welfare gains from optimal annuitization compared to no annuitization are substantial: the certainty equivalent consumption increases from $\$ 16,000$ to $\$ 25,000$. Davidoff, Brown, and Diamond (2005) and Mitchell, Poterba, Warshawsky, and Brown (1999) also find high welfare gains. Our goal is to determine whether full annuitization remains optimal if individuals face substantial medical expenses resulting from the exponential health cost specification. The solid line in Figure 2 depicts the certainty equivalent consumption, which is increasing in the annuitization level. Thus, health risk is not a reason to decrease annuity demand for this health cost specification. ${ }^{9}$ The benefits of insurance against longevity risk and the mortality credit outweigh the (initial) reduction in liquidity. Naturally, the attainable welfare levels decrease due to the health costs, but the curves are still essentially increasing: more annuitization leads to more utility. In the subsequent section we will see that the main difference between the case without health risk is that the agent accumulates wealth out of annuity income to cover health cost shocks and plans consumption to rebuild these buffers when needed. Hence it is vital that the health costs in early retirement years are low enough so that a retiree can build a large enough buffer out of the annuity income to insure against health costs later in life. In Section 4.2 we show that if the health costs can be high early in retirement, full annuitization is no longer optimal.

The previous results also hold for males. The dotted line in Figure 2 presents the case for males who

\footnotetext{
${ }^{8}$ French and Jones (2004) also include gender in the estimation, but this is a less extensive model than the model by De Nardi, French, and Jones (2010a).

${ }^{9} \mathrm{We}$ also tested whether this result holds if individuals can only invest in a nominal annuity. This does not change the results. The annuity income in real terms decreases over time with a nominal annuity, hence individuals can easily save in the first years of retirement to build a high enough buffer for later in life.
} 


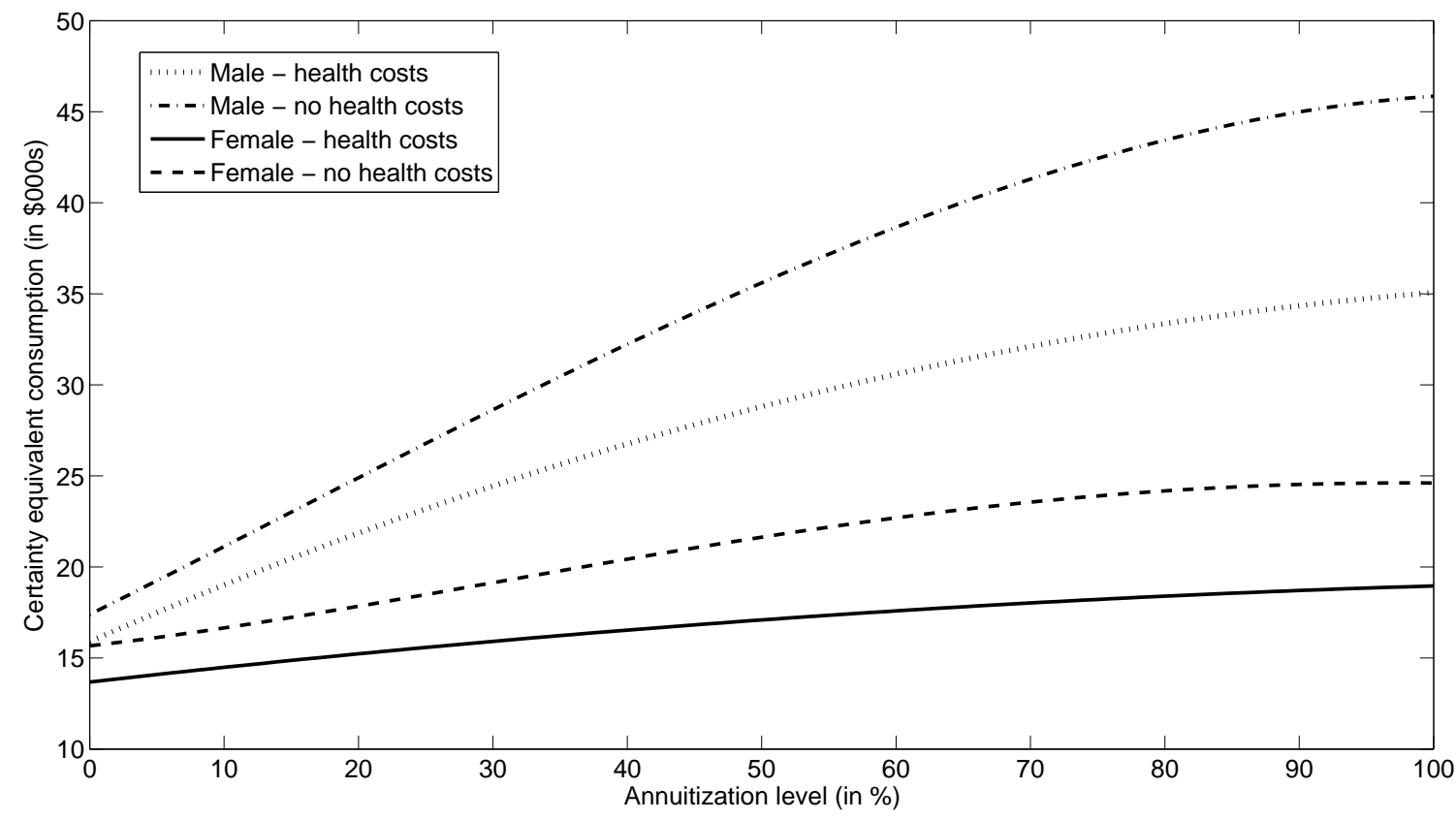

Figure 2: Optimal annuitization levels with exponential health costs

The figure displays the certainty equivalent consumption for the life cycle model with and without medical expenses for males and females. The optimal annuitization strategy is the level that generates the highest certainty equivalent consumption. The health cost specification employed is from De Nardi, French, and Jones (2010a), which we labeled the exponential health cost model.

face out-of-pocket medical expenses and, again, we see that full annuitization is optimal. This is not surprising since males face lower out-of-pocket medical expenses, hence need less liquid wealth to cover health expenses. Furthermore, we see in the figure that the certainty equivalent consumption for males is substantially higher. The reason for this is that health costs are lower and the annuity income for males is larger than for females. The income differs since both are actuarially fair for each group and calculated separately. As male life expectancy is lower, the annuity is cheaper. ${ }^{10}$

Pang and Warshawsky (2010) also use the health cost model of De Nardi, French, and Jones (2010a),

\footnotetext{
${ }^{10} \mathrm{We}$ also calculated whether our results hold if both males and females receive an annuity income calculated via the average survival probability of males and females. In that case full annuitization is still optimal. It is not optimal for a male to decrease demand, because the mortality credit is still high enough to induce full annuitization. Furthermore we tested whether our results hold when taking into account high end-of-life health costs. Among others, Werblow, Felder, and Zweifel (2007) find that proximity to death is a more important determinant of health costs than age. This strand of literature does not focus particularly on estimating out-of-pocket medical expenses, but looks at the impact of population ageing on insured health care expenditures (Seshamani and Gray (2004), Shang and Goldman (2007), and Weaver, Stearns, Norton, and Spector (2009)). In the health cost specifications we employed before, this proximity to death effect is not incorporated explicitly. Implicitly it is included to a certain extent, since expected medical expenses increase if the health status deteriorates, and health status and survival probabilities are positively related. However, to test for whether our results hold, we include a time-to-death effect according to the findings in Werblow, Felder, and Zweifel (2007). They find a large time to death effect in health costs and this difference in health costs between decedents and survivors decreases with age. At age 65, the medical expenses for decedents are about three times as high as for survivors, and this factor decreases to about two for 90-year olds. To incorporate this, we alter the medical costs of the exponential specification, by increasing the expenses in the year before death with a factor between 2 and 3, depending linearly on the age at death. The optimal annuity demand when we added the end-of-life costs did not change, hence our results our robust. This is intuitive since, the health costs have mostly only risen at advanced ages.
} 
but find that annuity demand increases due to health costs. The reason for this contrasting result is that they do not model annuitization as a one-time decision that is made at retirement, but instead, they optimize annually over the equity-bond-annuity portfolio. We assume that the annuity decision needs to be made at retirement for various reasons. First of all in several countries the decision whether to annuitize your pension account or take a lump sum takes place at retirement, due to tax legislation. A second reason for our assumption of a single conversion opportunity at retirement is that in reality people make financial decisions very infrequently. Furthermore Agarwal, Driscoll, Gabaix, and Laibson (2009) show that the capability of individuals to make financial decisions declines dramatically at higher ages, hence it seems optimal to make these decisions at younger ages when a person is still able to do so. Pang and Warshawsky (2010), in effect, modeled the annuitization decision as a portfolio allocation decision. Health costs are an additional risk factor which drives households to shift demand from risky to riskless assets, namely from equity to bonds and annuities. As a consequence of the superiority of annuities over bonds, annuity demand increases due to health costs.

As stated earlier, the reason that full annuitization is optimal is that individuals save sizeable amounts out of their annuity income to insure against high medical expenses. The benefits from receiving the mortality credit and insure against longevity risk exceed the initial loss of liquidity. In Figure 3 we present the median optimal consumption and wealth paths for three cases: (1) no annuitization, (2) full annuitization with health costs, and (3) full annuitization without health costs.

Figure 3 a shows that in case (1) of no annuitization, the optimal consumption path is decreasing over time. This reflects the fact that if the longevity risk in the real consumption level is not hedged, agents do not plan much consumption at ages where the probability is high that one will have passed away. If real annuities are used (case (3)), inflation risk can be hedged and the planned consumption path is approximately flat in real terms (in our specification the time preference parameter and interest rates coincide approximately). However, we see that if an individual faces out-of-pocket medical expenses (case(2)), the median consumption path is lower. This is because the individual saves substantial amounts to insure against health risk.

The optimal liquid wealth trajectories are displayed in Figure 3b. In case (1) where no annuities are bought, the median optimal wealth trajectory is decreasing over time. Individuals slowly dissave out of their liquid wealth. However, we find that if an individual invests optimally in a real annuity and faces health costs (case (3)), the individual saves sizeable amounts out of the annuity income to build a buffer against health costs. This savings buffer is not decumulated at advanced ages, because the health risk that agents face are sizeable especially at these advanced ages. At age 100 the agent consumes the entire buffer, because we assume a certain death at age 100. In case (2) the savings are low, because the agent does not face any health cost risk.

These high levels of precautionary savings are in accordance with Palumbo (1999), De Nardi, French, and Jones (2010a), and Love, Palumbo, and Smith (2008), who show that out-of-pocket medical expenses induce individuals to hold large amounts of precautionary savings. Later we find that it is key for full annuitization to be optimal, to be able to save fast enough in the early retirement years to cover health expenses (Section 5). If, however, health costs can already be high in early retirement it is not optimal to 


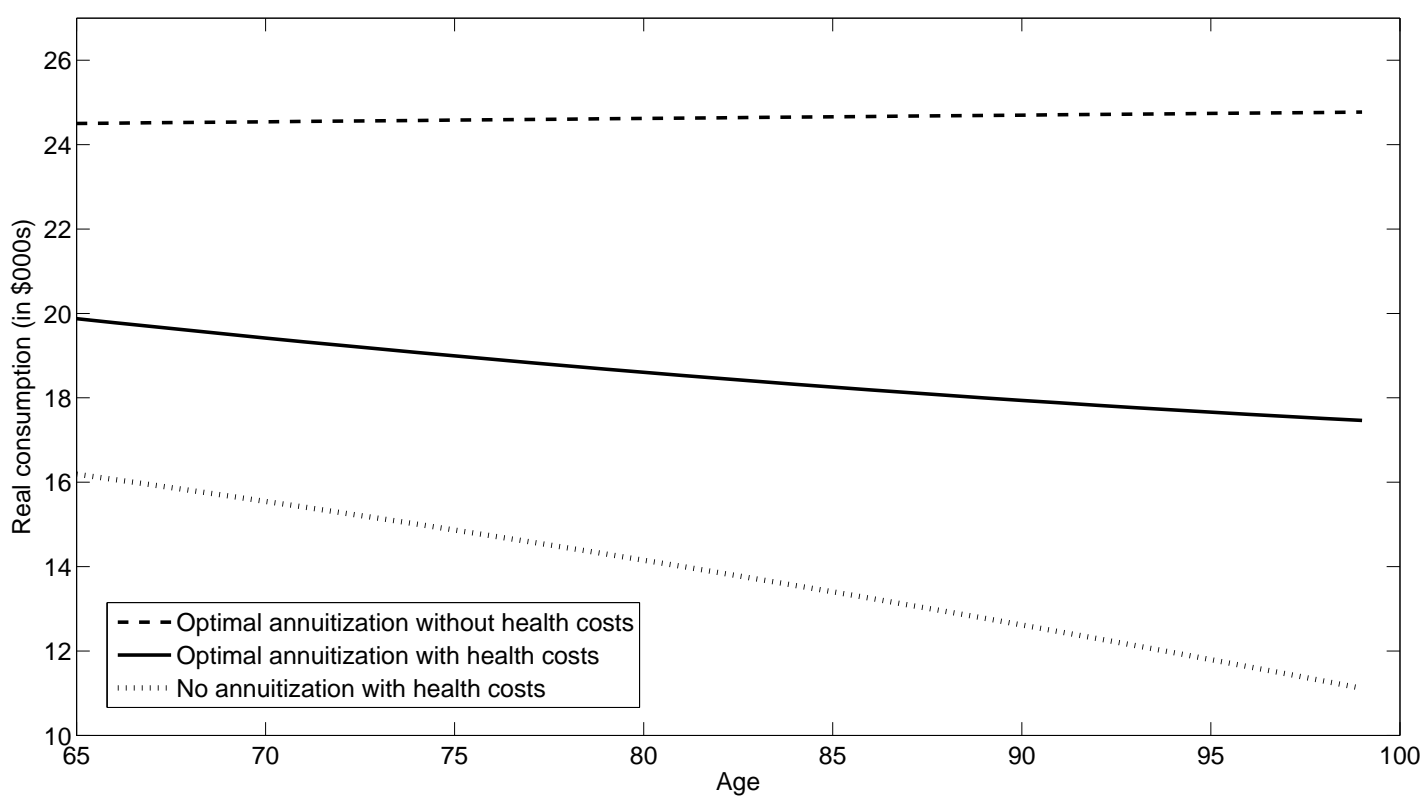

(a) Real consumption

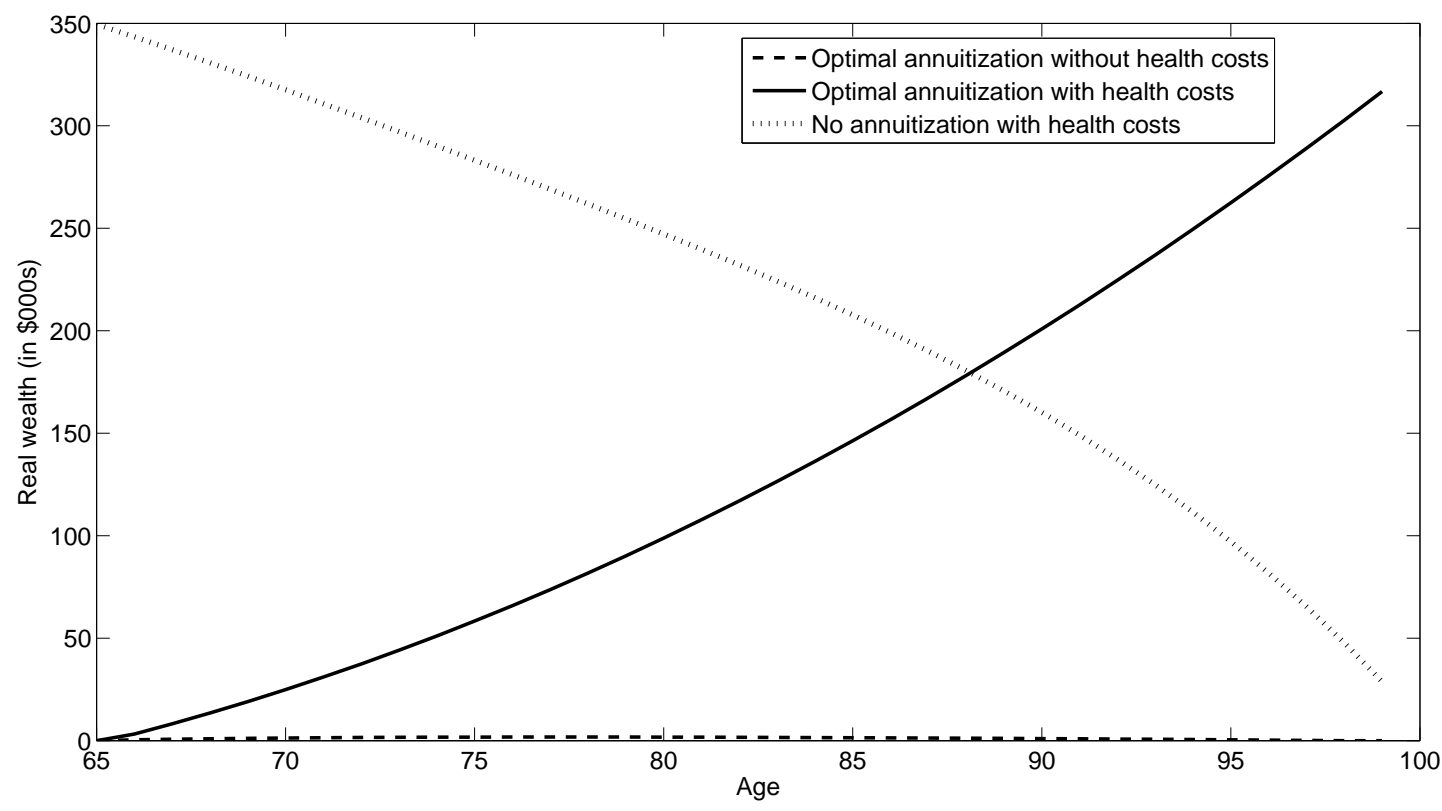

(b) Real liquid wealth

Figure 3: Optimal consumption

Panel (a) displays the median optimal real consumption for the optimal annuitization level when agents do not face health costs, optimal annuitization when agents do face health costs, and without annuities when agents face health costs. Panel (b) displays the optimal liquid real wealth for the optimal annuitization level when agents do not face health costs, optimal annuitization when agents do face health costs, and without annuities when agents face health costs. The optimal levels are for a female. The health cost specification employed is from De Nardi, French, and Jones (2010a), which we labeled the exponential health cost model. 
annuitize all wealth, since the retiree cannot save enough in a few years to cover these expenses. The only way to have a buffer against these expenses in early years, is to reduce the annuitization level. Furthermore we see in Figure $3 \mathrm{a}$ that the required buffer increases with age, because the health cost risk rises as agents get older. Hence the optimal consumption path decreases over time, because they need to save more to pay the expenses.

The optimal savings behavior is displayed in Figure 4. The annual savings out of the annuity income if an individuals has a wealth level of $\$ 50,000$ is approximately $\$ 5000$ per year for a 70 -year old female. However this savings level, for a given wealth level, increases sharply with age. A 80-year old and a 90-year old save $\$ 8000$ and $\$ 12,000$ respectively. The reason for this is that the expected health costs in the coming years are much higher. If an agent is still alive at advanced ages, he or she needs to build a buffer fast to be able to pay the expenses and smooth consumption.

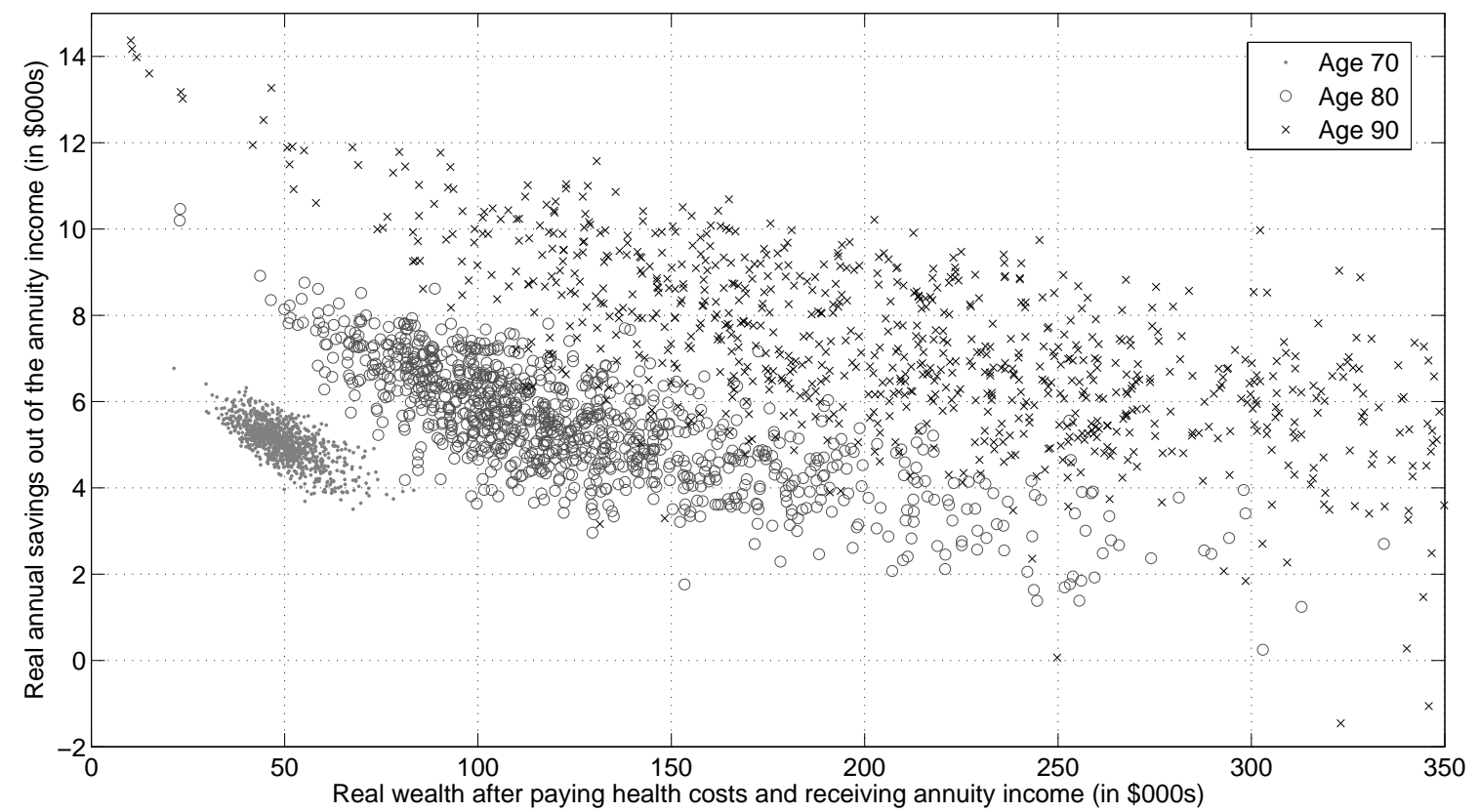

Figure 4: Optimal annual savings for varying wealth levels for a female age 70, 80, and 90 years old This graph displays the optimal simulated real savings for various real wealth levels. The liquid real wealth level is the amount of wealth after the individual received the annuity income and payed health costs. Hence it is disposable wealth, which the agent allocates to either consumption or saving. The vertical axes displays the optimal real savings out of the annuity income. The health cost specification employed is from De Nardi, French, and Jones (2010a), which we labeled the exponential health cost model.

\subsection{Optimal annuitization for various health cost specifications and wealth levels}

In the previous section we focussed on the optimal annuitization, consumption, and savings decisions for an agent who faces exponential health costs and has a mean wealth level and the benchmark minimum consumption level. In this section, we determine the optimal annuity demand for different health specifications, wealth levels, and minimum state guaranteed consumption levels. 


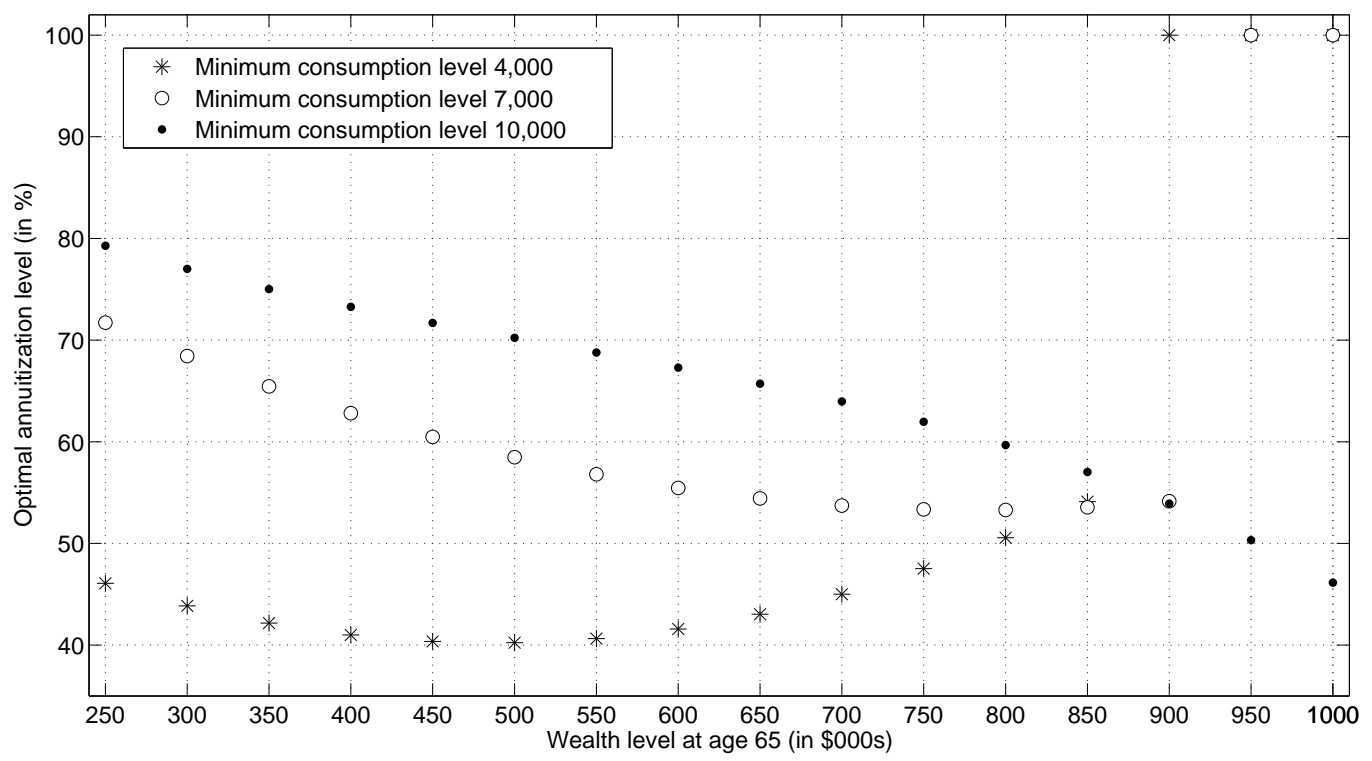

(a) Piecewise constant health cost model

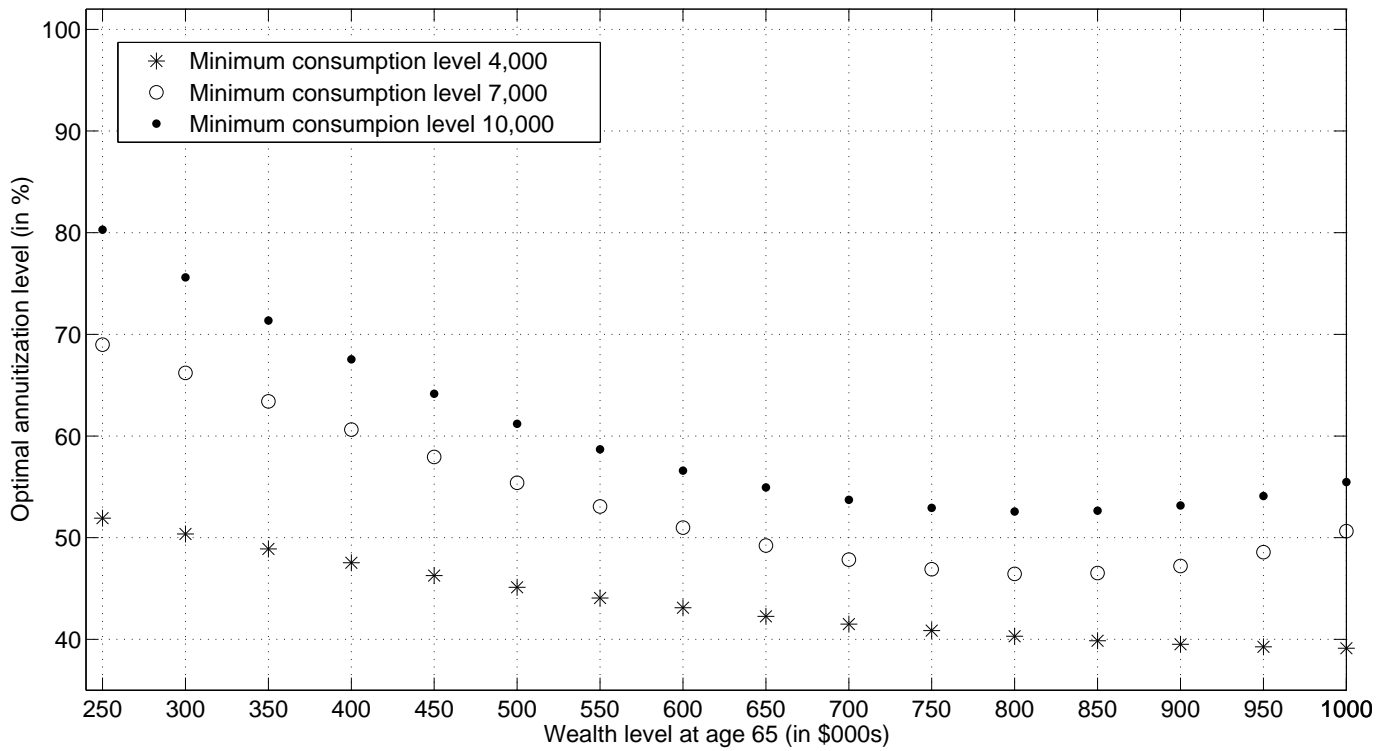

(b) Hump-shaped health cost model

Figure 5: Optimal annuity demand assuming the piecewise constant health cost model and hump-shaped health cost model, for varying wealth levels and minimum consumption level

The figure displays the optimal annuity demand for a 65 -year old female for varying wealth levels and minimum consumption levels. The numbers are in thousands of dollars. The health cost specification employed in panel (a) is from Ameriks, Caplin, Laufer, and Van Nieuwerburgh (2009), which we labeled the piecewise constant health cost model. The health cost specification employed in panel (b) is from Scholz, Seshadri, and Khitatrakun (2006), which we labeled the hump-shaped health cost model. The labels "piecewise constant" and "hump-shaped" correspond to the shape of the 99th percentile of health cost over the life cycle. 
Full annuitization is optimal when an agent faces exponential health costs or linear health costs. This finding holds for all wealth levels and minimum consumption levels we examined. The corresponding graphs are not presented in the paper. However, full annuitization no longer holds for the piecewise constant health cost specification and the hump-shaped health costs, which is displayed in Figure $5 .{ }^{11}$ This is in accordance with Ameriks, Caplin, Laufer, and Van Nieuwerburgh (2009) who find a similar result: Note that the health cost model which we labeled "piecewise constant health costs", is the specification of Ameriks, Caplin, Laufer, and Van Nieuwerburgh (2009). They estimate the willingness to pay (WTP) for an annuity with a price of $\$ 85,000$ which generates an income of $\$ 5000$ per year, for a healthy 62-year old female who has about $55 \%$ of wealth pre-annuitized. ${ }^{12}$ They find a WTP for this annuity of $0.94 .^{13}$

Whether full annuitization is optimal critically depends on the health cost specification. More precisely, the health costs in the piecewise constant health cost model and the hump-shaped model can already be large early in retirement, which results in a lower optimal annuity demand. This can be seen from Figure 1c for both models: there is a $1 \%$ probability to incur health costs of at least $\$ 50,000$ already at age 66 . In that case an individual cannot save enough in the first years of retirement to insure against high expenses in these years. Since the costs in utility terms of receiving the minimum consumption level are high, an individual will annuitize only part of wealth to be able to smooth consumption in case of high health costs. In Section 5 we develop a rule of thumb for annuity demand which closely mimics these effects.

We see in both panels that, for a given minimum consumption level, annuitization levels exhibit a Ushaped pattern. If the wealth level at retirement is low, high annuity levels are optimal. In Panel 5a we see for a total wealth level of $\$ 250,000$ at age 65 , it is optimal to invest $80 \%$ in annuities if the minimum consumption level is $\$ 10,000$. This is because the difference between the normal consumption level and the minimum consumption level is not that high. In numbers; a wealth level of $\$ 250,000$ can generate an annuity income of about $\$ 15,000$, which differs only $\$ 5000$ from the minimum consumption level. If an individual is hit by a large health cost shock and receives the government guaranteed consumption level, this is not so costly in utility terms, because the fall in consumption is not so high.

For intermediate wealth levels, the fall in utility is larger if hit by a health shock, because the difference between the normal (annuity) income and the minimum consumption level is higher. For this reason it is optimal to reduce annuity demand to be able to smooth consumption and prevent consuming only the minimum level. For higher wealth levels, the optimal demand rises again. If the wealth level is higher it is easier for agents to build up a buffer fast to insure against health shocks. At a certain wealth level, the annuity income is so high that an agent can always pay the health costs and still have a consumption level above the minimum. The health costs in the piecewise constant model are deterministic and the maximum is $\$ 50,000$. Hence if the wealth level is high enough, then the resulting annuity income minus $\$ 50,000$ is higher than

\footnotetext{
${ }^{11}$ In Section 3.3 we labeled the health cost specification estimated by De Nardi, French, and Jones (2010a) as the exponential health costs, Ameriks, Caplin, Laufer, and Van Nieuwerburgh (2009) as piecewise constant health costs, Scholz, Seshadri, and Khitatrakun (2006) as hump-shaped health costs, and the model by French and Jones (2004) as linear health costs. We choose these labels to reflect the shape of the out-of-pocket medical expenses over the life cycle.

${ }^{12}$ The income from pre-annuitized wealth level corresponds to a wealth level of about $\$ 375,000$ and her liquid wealth is $\$ 300,000$. Hence total wealth is $\$ 675,000$. In effect the agent is choosing between annuitizing $55 \%$ of wealth or annuitizing almost $70 \%$ of wealth.

${ }^{13}$ The willingness to pay reflects the load on top of the actuarially fair price that the individual is willing to pay for this product. Hence a WTP of 0.94 means that the individual would even need a $6 \%$ bonus to hold the annuity.
} 
the minimum level. In that case, full annuitization is optimal and the utility increases much, because the minimum level of consumption ever hit (annuity income minus \$50.000), increases. This wealth threshold is higher, for higher minimum consumption levels, which can also be seen in Figure 5. Analogue to our finding of a non-linearity in optimal annuitization levels, Ameriks, Caplin, Laufer, and Van Nieuwerburgh (2009) find a similar non-linearity in savings motives. Comparable to our reasoning, they explain that agents with high wealth and income levels have less incentives to save, because they have enough income to pay their medical expenditures. While, on the other hand, poor individuals can never save enough to be able to afford the high medical costs. However the incentives to save are especially high for intermediate income and wealth levels.

Furthermore, for a given wealth level, the optimal annuity demand is higher for higher minimum consumption levels (if the aforementioned wealth threshold is not hit). The reason for this finding is that if an agent incurs large health costs, the drop in utility is larger for lower minimum consumption levels. Under those circumstances, an individual is induced to hold a larger amount liquid to be able to smooth consumption and avoid receiving the minimum consumption level. This is also clear from Figure 5, by comparing the optimal annuity demand for varying minimum consumption levels.

Summarizing, optimal annuity demand depends critically on three factors: (1) the cumulative health costs in the first retirement years, (2) the savings ability (wealth) in the first years to cover these costs, and (3) the drop in utility from the normal consumption level compared to the minimum level. In Section 5, we summarize these variables in a simple rule of thumb for the optimal annuitization level. Since the optimal demand depends only on these simple inputs, a rule of thumb is useful. Many financial service providers are advising agents on how to manage their money during retirement. Furthermore the need for advice will increase over time as the Baby Boom Generation reaches retirement, seeking help on how to manage their retirement wealth. Given that health risk is the main risk that the elderly face, a simple rule for annuity demand which takes this into account is beneficial. In the next section we develop a rule of thumb for the optimal annuity demand. This rule will give the optimal annuity level for an individual depending on only three key variables, amount of cumulative health costs in the first 5 years incurred with a $1 \%$ probability, the amount of wealth at retirement, and the minimum consumption level.

\subsection{Sizeable health risk early in retirement can explain the annuity puzzle for all wealth levels}

In Section 4.2 we show that if the health costs can be sizeable early in retirement, optimal annuity demand is decreased. In contrast to Ameriks, Caplin, Laufer, and Van Nieuwerburgh (2009) we determine the optimal annuity demand for varying wealth levels, and we show that the optimal demand depends highly on the wealth level at retirement. In the literature a lot of attention is devoted to explaining the low empirically observed annuity levels: the annuity puzzle. However, whether there is really a "puzzle" depends on the wealth level of the individual. The empirically established annuity levels for high wealth levels can be as low as $50 \%$, compared to levels of about $95 \%$ for less wealthy individuals. Dushi and Webb (2004) determine the pre-annuitized fraction of wealth at age 65 of a single female for various wealth levels, which is displayed in Figure 6. When we compare these empirical annuitization levels with the optimal levels, we detect a similar 


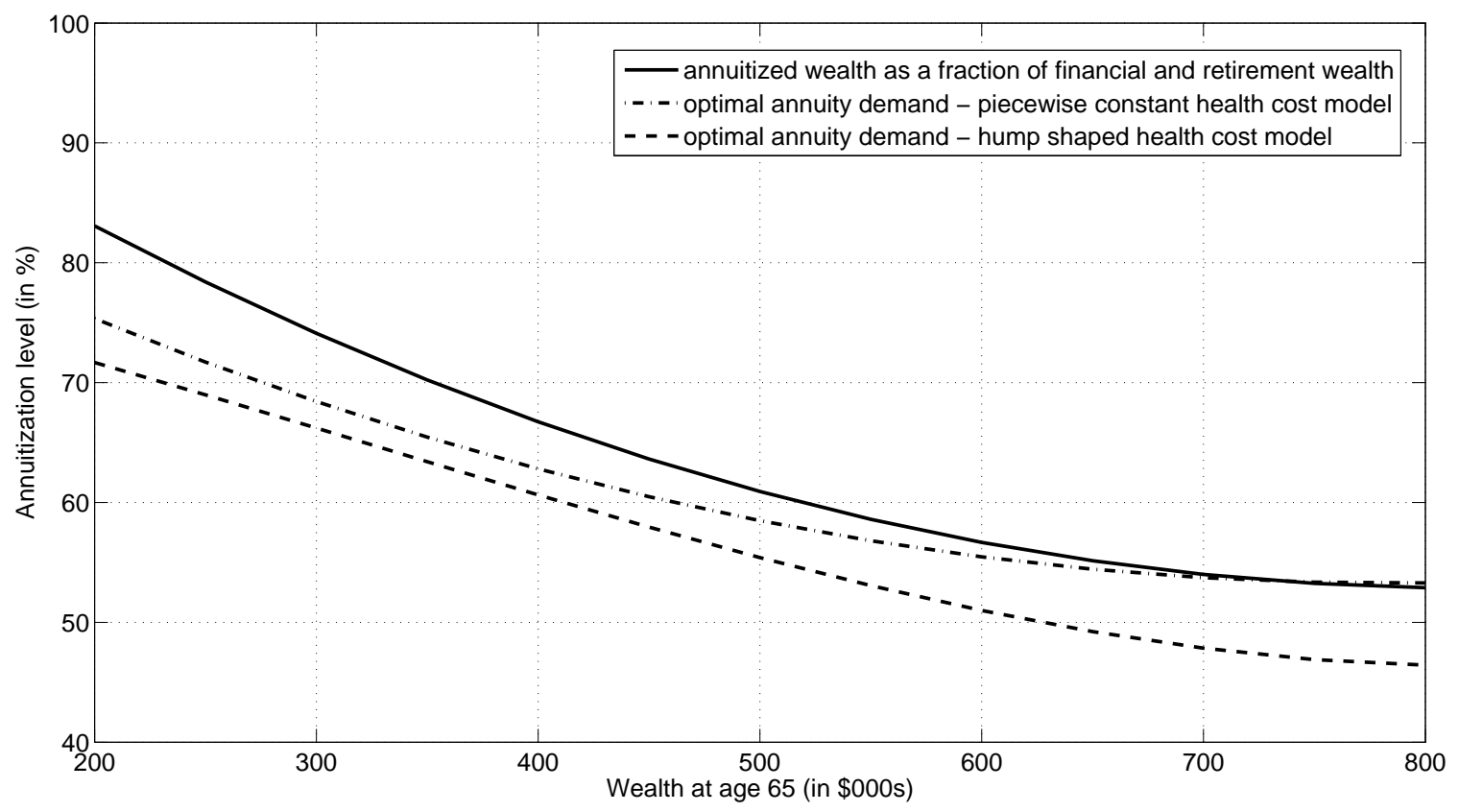

Figure 6: Optimal annuity demand and pre-annuitized wealth levels.

We display the pre-annuitized wealth level for a single female at age 65 estimated in Dushi and Webb (2004). They use data from the HRS to estimate the fraction of wealth annuitized as a percentage of the sum of financial and retirement wealth. Financial wealth includes the business assets, financial assets, and IRA's. Retirement wealth includes social security, DB pensions, and DC pensions. Furthermore we document the optimal annuity demand for the piecewise constant health costs and hump-shaped health costs.

pattern. We see that for the piecewise constant and the hump-shaped health cost specification, the optimal annuity demand is below the pre-annuitized level, for all wealth levels. Hence if the medical expenses, that is their subjective expectation, can be high early in retirement, health cost risk can explain the annuity puzzle. Furthermore, the health costs cannot only explain the annuity puzzle when all wealth levels are aggregated, but also the empirical relationship between annuity levels and wealth. If agents face health cost risk it is optimal for low wealth households to hold a large fraction in annuities, compared to high wealth households, who should optimally annuitize less. Thus the annuity levels empirically observed and the lack of additional annuity purchases (the annuity puzzle) can be explained by high health cost risk early in retirement.

\subsection{Robustness tests for the effect of high health risk early in retirement on annuity demand}

In our baseline set up we ignored several factors which could have an effect on optimal annuity demand; (1) housing as a potential source of liquidity, and (2) a change in marginal utility due to a change in health status. In this section we examine the effect of these factors on optimal annuity demand and check whether our main results still hold. 


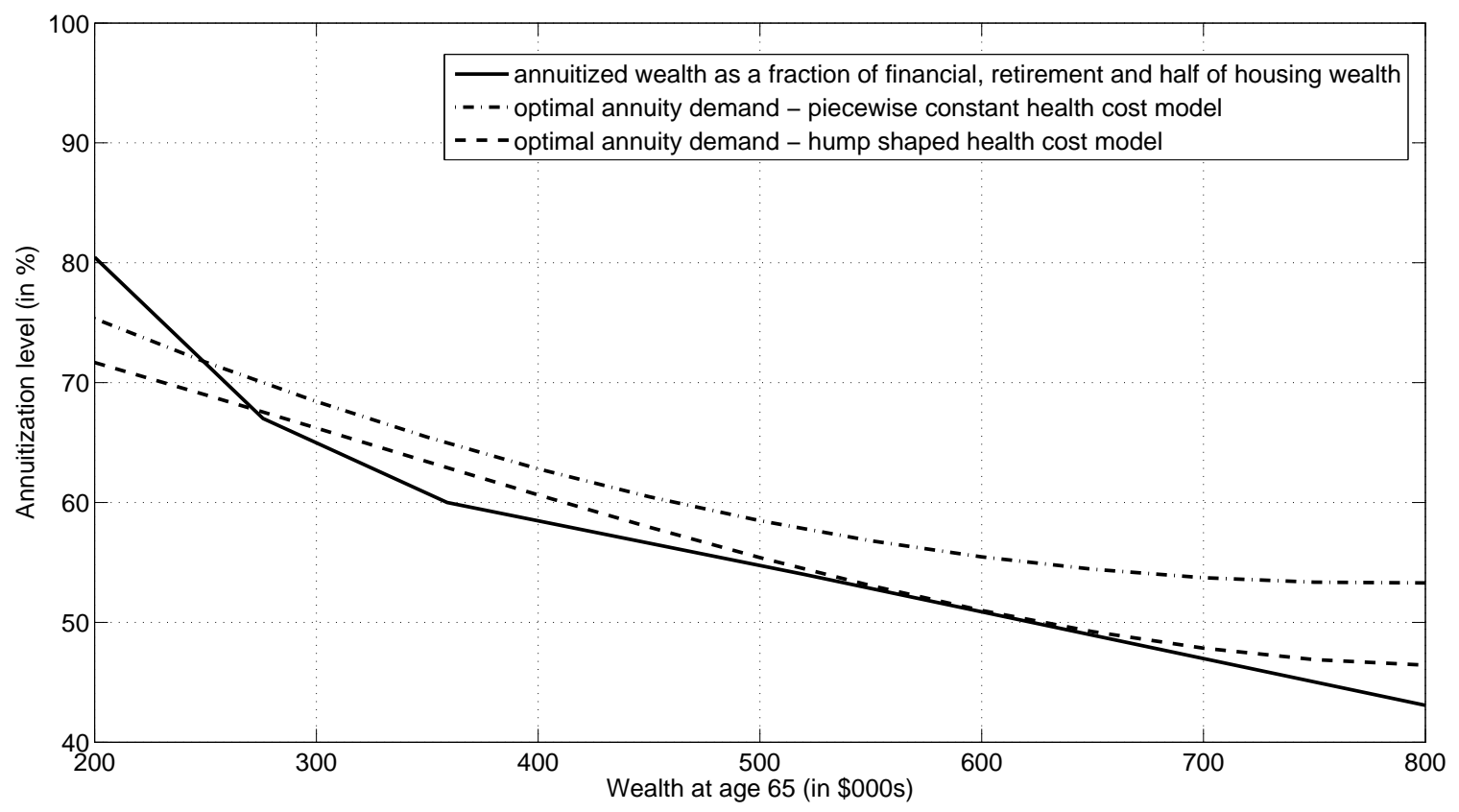

Figure 7: Optimal annuity demand and pre-annuitized wealth levels; housing wealth included.

We display the pre-annuitized wealth level for a single female at age 65 estimated in Dushi and Webb (2004). They use data from the HRS to estimate the fraction of wealth annuitized as a percentage of the sum of financial, retirement, and half of housing wealth. Financial wealth includes the business assets, financial assets, and IRA's. Retirement wealth includes social security, DB pensions, and DC pensions. Housing wealth is the wealth net of mortgage. Furthermore we document the optimal annuity demand for the piecewise constant health costs and hump-shaped health costs.

\subsubsection{Housing as a source of liquidity}

In our baseline case, we abstract from housing wealth as a way to get liquidity for a number of reasons. First, it is extremely costly to get a reverse mortgage. Closing costs are on average about $6.8 \%$ of the property value (Davidoff and Welke (2007)). Davidoff and Welke (2007) note that these high closing costs are cited as one of the major reasons for the relative small demand for reverse mortgages. Rodda, Herber, and Lam (2000) report that a Home Equity Conversion Mortgage (HECM) borrower has a median adjusted property value of about $\$ 102,000$, median initial principal limit of $\$ 54,000$, and median closing costs of $\$ 3400$. Given that the net of mortgage housing wealth of a single female with a median wealth level is about $\$ 30,000$ and for a couple is about $\$ 82,000$ (Dushi and Webb (2004)), the amount that the median agent can borrow is limited and thus provides only partial insurance against medical expenses. Second, empirical evidence shows that retirees generally do not sell their house, which is also a way to liquidate housing wealth. Yang (2009) finds that transaction costs are a major factor in the slow downsizing of the housing stock later in life. This is further supported by Davidoff (2010) and Venti and Wise (2000) who show that retirees typically only sell their house when they move to a long term care facility. Individuals appear to attach a high value to remaining in their home and not having to move.

As a robustness test we assume that half of housing wealth can be made liquid and the results are displayed in Figure 7. The wealth at age 65, displayed on the horizontal axes, presents total wealth, which is 


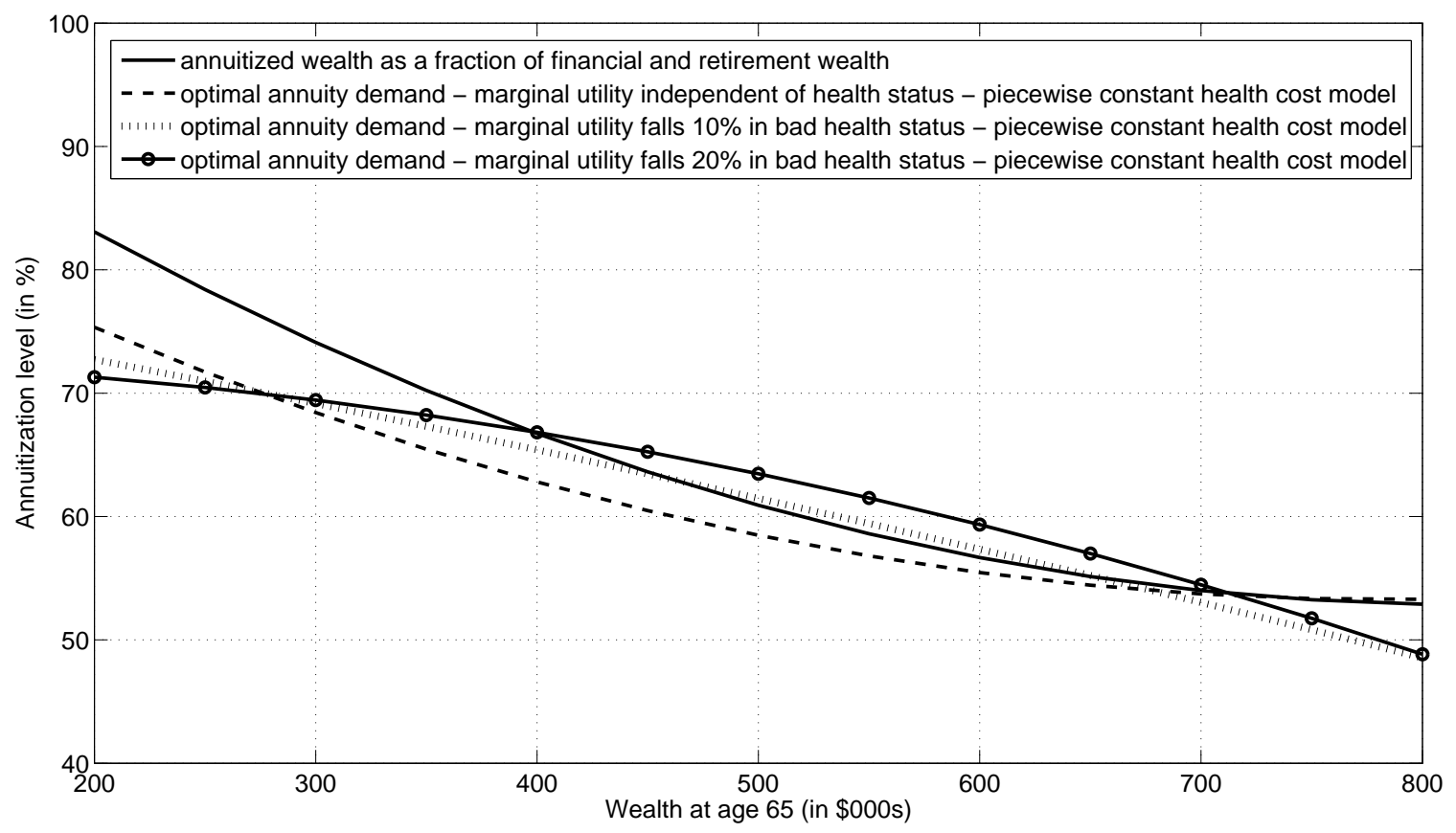

Figure 8: Optimal annuity demand and pre-annuitized wealth levels; marginal utility health state dependent. The optimal annuity demand is for the piecewise constant health cost model. We display the pre-annuitized wealth level for a single female at age 65 estimated in Dushi and Webb (2004). They use data from the HRS to estimate the fraction of wealth annuitized as a percentage of the sum of financial and retirement wealth. Financial wealth includes the business assets, financial assets, and IRA's. Retirement wealth includes social security, DB pensions, and DC pensions. Furthermore we document the optimal annuity demand for the piecewise constant health costs and hump-shaped health costs.

the sum of financial wealth, retirement wealth, and half of housing wealth. Hence when comparing Figure 6 and 7 the definition of total wealth has changed; in Figure 6 we abstracted from housing wealth while in Figure 7 we assume that half of housing wealth can be made liquid and is thus included in the measure of total wealth. ${ }^{14}$ We see that the empirically observed annuitization levels are higher than the optimal levels for a wealth level lower than $\$ 300.000$ and opposite for wealth levels above $\$ 300.000$. However, for the relevant range of wealth levels the difference between the optimal and observed annuity levels is neglible; namely the median wealth level is about $\$ 200.000$, 7th decile is $\$ 270.000$, and the 9th wealth decile is $\$ 500.000$. In accordance with our results, Pashchenko (2010) finds that the effect of housing wealth on participation in the annuity market is limited. Note that although in the optimization we implicitly allow for liquidation of half of housing wealth and annuitization of this, we find that this is not optimal. We already saw in Figure 6 that people do not want to annuitize their entire retirement plus financial wealth, hence it is not optimal to annuitize, on top of this, housing wealth. 


\subsubsection{State dependence of marginal utility}

As a further robustness test we make the marginal utility of consumption dependent on the health status of the agent. We did not include this in the baseline case, because there is no consensus in the literature on the relative change in marginal utility or even on whether the marginal utility is higher or lower in a bad health status (Edwards (2008) and Viscusi and Evans (1990)). ${ }^{15}$ Recently Finkelstein, Luttmer, and Notowidigdo (2008) find that the marginal utility declines as the health state deteriorates and estimate that a one-standard deviation increase in the number of chronic diseases leads to a decrease in marginal utility of 11 percent. In Figure 8 we display the optimal annuitization levels when the marginal utility in the bad health state declines by $10 \%$ or $20 \%$. The optimal annuity demand is altered only slightly hence our results are robust to health state dependence of the utility from consumption. We cannot perform this robustness test for the hump shaped health cost model, because the health status is not modeled for that health cost specification.

\subsection{Discussion on the likelihood of high health cost risk early in retirement}

Given the wide variety of estimated processes for health costs we cannot make a conclusive statement on whether health cost risk is high early in retirement. There is, however, compelling evidence pointing in this direction. The largest health cost risk that agents face are long term care costs. Therefore, when assessing the risk early in retirement, utilization rates of nursing homes during those ages are particularly relevant. Brown and Finkelstein (2007) estimate that the probability that a 65-year old is in a nursing home or assisted living at age 70 is $0.7 \%$ and $0.5 \%$ for respectively females and males. ${ }^{16}$ This is conditional on being eligible for purchasing long term care insurance. ${ }^{17}$ Hence the risk of going to a nursing home early in retirement is much higher than this $0.7 \%$, because this number is based on the least risky 65 -year olds. Murtaugh, Kemper, and Spillman (1995) estimate that about $12 \%$ to $23 \%$ of the 65 -year olds would be rejected for private long term care insurance. Admittedly, this is all anecdotal evidence, but it does provide an indication for the probability of high health cost risk early in retirement.

When comparing the health cost processes that we use, note that the piecewise constant health cost model (Ameriks, Caplin, Laufer, and Van Nieuwerburgh (2009)) matches the empirical utilization levels of long term care at different ages and find that health cost risk is already high early in retirement. On the other hand, the exponential health cost model (De Nardi, French, and Jones (2010a)) finds low health cost risk early in retirement. However this can be (partially) attributed to the dataset that is used to estimate the health cost process of the exponential model. Namely the individuals in the AHEAD dataset, which is a part of the HRS, are non-institutionalized and over 70 at the start of the survey in 1994. Therefore the estimation of the health cost process is based on a relatively healthy subsample of the population and understates the health cost risk early in retirement, but not so much at later ages. In addition, De Nardi, French, and Jones

\footnotetext{
${ }^{14}$ Note that the empirically observed annuitized fraction of wealth, when we take half of housing wealth into account, is of course lower than if we abstract from housing wealth. Furthermore the optimal annuity demand as a fraction of total wealth has not changed, only the meaning of wealth on the horizontal axes is altered.

${ }^{15}$ An overview of this literature is provided in Finkelstein, Luttmer, and Notowidigdo (2009)

${ }^{16}$ Note that only $4 \%$ of long term care costs is covered by private insurance and that costs of living in a nursing home amount to at least $\$ 50.000$ a year.

${ }^{17}$ The distinction on being eligilble for purchasing long term care insurance is not relevant for our paper. This is however the only estimate of transition probabilities into a nursing home from age 65 to 70 that we could find in the literature.
} 
(2010a) note that their estimates potentially underestimate the out-of-pocket expenses for another reason. The expenses reported in the HRS do not include payments made by medicaid when agents could not pay for the out-of-pocket costs themselves. So when simulating the out-of-pocket expenses, a substantial part of these out-of-pocket costs is in the simulations not actually payed "out-of-pocket", in case agents did not have enough wealth and received the minimum consumption level. For this reason the out-of-pocket expenditure risk is underestimated in the exponential health cost model. This is also the case for the hump-shaped health cost model and the linear health cost model.

\section{Rule of thumb for optimal annuitization}

Since the health cost risk early in retirement is the main determinant of optimal annuity demand, a simple rule depending on this statistics would be useful, e.g. for personal financial planning. In this manner we can better understand the drivers of optimal annuity demand. The idea of the rule of thumb is that it gives the optimal annuitization decision in an extremely stylized problem. In particular, the stylized problem is solved myopically, which simplifies the analysis enormously. We describe the stylized problem in the subsequent section. In Section 4.2, we found a U-shaped pattern: for both high and low wealth levels, (almost) full annuitization is optimal. For high wealth levels, the retiree can pay his health costs out of his annuity income and still have a consumption level higher than the minimum level. For agents with low wealth, high annuitization levels are also optimal, because the difference between the normal consumption and the minimum level is small. However, for intermediate levels, high annuity demand is not optimal if the health costs can be sizeable early in retirement. Our rule of thumb leads to the same pattern.

Given the variety of health cost models in the literature with different estimated processes, we cannot conclude definitively whether health cost risk early in retirement is indeed high. However, for using the rule of thumb this is irrelevant. The subjective assessment of an individual of health cost risk early in retirement is the only statistic necessary to determine optimal annuity demand for this retiree.

\subsection{Stylized market and problem}

We consider a myopic expected utility maximizing agent in a financial world without inflation and with only risk-free investments available at interest rate $r$.

The agent is exposed to health shocks that, for periods 1 to $s$ (we take $s=5$ years), are either zero with probability $1-p>0$, or some (large) positive amount $H$, with probability $p>0$. Hence an individual incurs health costs for all $s$ subsequent years or not at all. Health costs are thus highly persistent. For the periods $s+1$ and later, health costs are assumed to be zero by the agent, possibly due to mental discounting. The agent has at the beginning of period 1 free wealth $W$ available.

The choice problem the agent faces is how much of the initial free wealth $W$ to save (and thus how much to keep liquid, denoted by $S$ ) and how much, the rest $(W-S)$, to put in annuities at period zero that will pay $(W-S) / A_{1, r}$ for the remaining lifetime. $A_{1, r}$ is the annuity factor and is taken from the four health cost models. 
When the individual is not hit by a health shock, the agent consumes the following amount for $\tau$ years (recall the agent is myopic):

$$
\frac{W-S}{A_{1, r}}+\frac{S(1+r)^{z}}{A_{s}}
$$

where $\tau$ is the life expectancy, $A_{1, r}$ is the annuity factor, and $A_{s}$ is the age reached with some probability that we will fix at $35 \%$. Hence the agent draws his wealth down slower than with his life expectancy, to decrease his longevity risk.

When the individual does face health costs, consumption is

$$
\begin{aligned}
\frac{W-S}{A_{1, r}}+\frac{S(1+r)^{k}}{s}-H & \text { for } \quad t=1: s, \\
\frac{W-S}{A_{1, r}} & \text { for } \quad t=s+1: \tau .
\end{aligned}
$$

The parameter $k$ is determined in a similar way as $z$, i.e., $k$ is set in such a way that $S(1+r)^{k}$ is equal to the total amount of savings including interest rate return if a fixed annual amount is subtracted for $s$ years. There is no draw down of savings after period $s$, because the amount of savings will never be higher than $s H$. This amount would completely insure against health risk, and there is no reason to save more. In this stylized model, no additional reasons to save are incorporated such as equity exposure or other background risks. Since $S$ will never be higher than $s H$, the savings buffer will, in case of a health shock, be depleted completely after period $s$, hence the individual consumes his annuity income, $(W-S) / A_{1, r}$ from period $s+1$ to $\tau$.

Using the utility function in (2), the total expected utility is given by

$$
\begin{array}{r}
(1-p) A_{1: \tau} u\left(\frac{W-S}{A_{1, r}}+\frac{S(1+r)^{z}}{A_{s}}\right)+ \\
p A_{1: s} u\left(\max \left(\frac{W-S}{A_{1, r}}+\frac{S(1+r)^{k}}{s}-H, C_{\text {min }}\right)\right)+p A_{s+1: \tau} u\left(\frac{W-S}{A_{1, r}}\right)
\end{array}
$$

where $A_{1: \tau}$ is the sum of betas from 1 to $\tau$. This total expected utility is maximized with respect to the choice variable $S$.

\subsection{Effectiveness of the rule of thumb}

In Section 4, we found that the optimal annuity demand depends crucially on the distribution of health costs. Furthermore, the minimum consumption level and the wealth level are important variables to determine the optimal annuitization level: the ratio between both determines the magnitude of the fall in consumption if hit by a health shock.

To operationalize our rule of thumb, we need to determine the health cost level $H$. We consider the cumulative health costs in the first 5 years of retirement and set the health costs, $H$, equal to the $1 \%$ quantile of these costs divided by 5 (since these costs are incurred for 5 years). Hence the procedure is as follows; calculate the cumulative health costs in the first 5 retirement years, take the $1 \%$ quantile, and divide by 5 . 
Subsequently this is put in the rule of thumb to determine the optimal savings level. We determine $H$ for the four health cost models and find medical expenses early in retirement of $\$ 13,000, \$ 42,000, \$ 44,000$, and $\$ 10,000$ for respectively the exponential, piecewise constant, hump-shaped and linear health cost model.

The welfare loss from using the rule of thumb are reported in Table 2. The rule of thumb does remarkably well; the welfare loss from using the rule of thumb instead of the full model is at most $3.4 \%$. The approximation via the rule of thumb is exact for the exponential and linear model. In those specifications the health costs early in retirement are small, hence both the rule of thumb and the life cycle model find an optimal annuity demand of $100 \%$. The optimal annuity demand is reported in Appendix B. The rule of thumb does not give precisely the same annuity demand compared to the full model for the piecewise constant and hump-shaped health cost models. The health costs can be high early in retirement hence the optimal annuity demand is less than $100 \%$. However the welfare costs from using the rule are small; the maximum loss is $3.4 \%$, which is only a small fraction of the welfare loss that can occur due to suboptimal annuity strategies.

Table 1: Comparison rule of thumb and full model

In this table we report the welfare costs from using the rule of thumb instead of the full life cycle. Naturally, the main input in the rule of thumb, the health costs in the first five years of retirement differs in the four models. The health costs are $\$ 13,000$, $\$ 42,000, \$ 44,000$, and $\$ 10,000$ for respectively the exponential, piecewise constant, hump-shaped, and linear model. Throughout, a minimum consumption level of $C_{\min }=7000$ is used. The survival probabilities are different in all four models, hence the annuity factor, life expectancy, and the age that individuals reach with a $35 \%$ probability also differs.

\begin{tabular}{c|cccc}
\hline \hline total wealth & exponential & piecewise constant & hump-shaped & linear \\
\hline 200,000 & $0 \%$ & $1.7 \%$ & $1.2 \%$ & $0 \%$ \\
300,000 & $0 \%$ & $3.4 \%$ & $2.6 \%$ & $0 \%$ \\
400,000 & $0 \%$ & $0.2 \%$ & $0.3 \%$ & $0 \%$ \\
500,000 & $0 \%$ & $0.2 \%$ & $0.1 \%$ & $0 \%$ \\
600,000 & $0 \%$ & $2.7 \%$ & $0.9 \%$ & $0 \%$ \\
700,000 & $0 \%$ & $3.0 \%$ & $2.4 \%$ & $0 \%$ \\
\hline \hline
\end{tabular}

We show that the dependence of the optimal annuitization level on wealth using the rule of thumb mimics that of the full model. Take a closer look at the expected utility (19). Total expected utility (19), consists of three terms, where the first and the last are strictly decreasing in savings (S). Hence if the maximum in the second term is $C_{\text {min }}$ (and as a consequence does not depend on $\mathrm{S}$ ) then the optimal savings amount is zero. The intuition for this result is clear if we examine the second term;

$$
\max \left\{(W-S) / A_{1, r}+S(1+r)^{k} / s-H, C_{\min }\right\}
$$

more closely. The first argument of the maximum in (20) is increasing in S, so an increase in savings means a higher expected utility. But this first term only enters the expected utility function in case it exceeds $C_{m i n}$. Hence a higher minimum consumption level will lower the times the left term will enter the utility function. As a result, the optimal annuitization level increases, in case the minimum consumption level increases. Because the fall in utility, if you are hit by a health shock, is less costly in utility terms, the higher the minimum consumption level is. Hence, for low wealth levels the optimal level according to the rule of thumb is $100 \%$. Furthermore note that the higher the health costs are, the more likely it is that the left hand side of the formula is smaller than the minimum consumption level. Thus for a given wealth level, the 
probability of saving goes down. But if an agent saves, the savings are substantial.

Summarizing, the rule of thumb gives a good approximation of the optimal annuity demand, with welfare losses much smaller than generally reported in the literature on annuitization decisions. It finds the exact same result as the full life cycle model for the exponential and linear health cost models, and similar results for the piecewise constant and hump-shaped specification. The welfare loss from using the simple rule is small. The optimal annuity demand depends highly on the distribution of health costs in early retirement and initial wealth levels, but our rule of thumb parallels this dependence despite being myopic.

\section{Conclusion}

We examine the effect of out-of-pocket medical expenses on optimal annuity demand. Medical expenses increase the need for liquidity, which could induce households to annuitize less and keep wealth liquid. In the literature, several health cost specifications are estimated, which all imply a different process for out-of-pocket medical expenses. We employ four health cost models to disentangle an important driver of annuity demand: health cost risk early in retirement. We find that whether full annuitization remains optimal depends mainly on the amount of health cost risk early in retirement. If health costs can be sizeable early in retirement, an agent that annuitizes all wealth does not have enough time to build up a buffer against health cost risk and smooth consumption. In contrast, if the medical expenses are only moderately high, it is optimal to fully annuitize and subsequently save sizeable amounts out of the annuity income to build up a buffer. If in that case the agent is hit by a health shock later during retirement, the savings are high enough to pay the health expenses and smooth consumption. Extending Ameriks, Caplin, Laufer, and Van Nieuwerburgh (2009), we find that optimal annuity demand varies with initial wealth levels. When faced with high health cost risk early in retirement, agents with a low wealth level find it optimal to annuitize a large fraction while retirees with higher initial wealth levels optimally annuitize less. We compare these optimal annuity levels with the empirically observed annuitization levels for varying wealth levels and find a similar pattern. Both the empirically observed annuity demand and the optimal annuity demand is decreasing in the wealth level if the health costs can be high early in retirement. Furthermore the optimal demand is lower than the empirically established annuitization level for all wealth levels, hence we can explain the annuity puzzle.

As the Baby Boom Generation approaches retirement, it is seeking financial advice on how to manage their retirement assets. Given that health risk is the most important risk an elderly faces, a simple rule for annuity demand which takes this into account is particularly useful for financial planning purposes. We derive a rule of thumb from a stylized model to determine optimal annuity demand. The key input, which the agent needs to subjectively assess, is whether he or she thinks there is a small probability of facing high health costs in the coming 5 years. This is a fairly easy assessment to make. Welfare costs of using this rule instead of the full life cycle model are between $0 \%$ and $3.4 \%$, for the four health cost models we tested. 


\section{References}

Agarwal, S., J. Driscoll, X. GabaiX, and D. Laibson (2009): “The Age of Reason: Financial Decisions over the Life-Cycle with Implications for Regulation," forthcoming, Brookings Papers on Economic Activity.

Ameriks, J., A. Caplin, S. Laufer, and S. Van Nieuwerburgh (2009): "The Joy of Giving or Assisted Living? Using Strategic Surveys to Separate Public Care Aversion from Bequest Motives," Working paper, available at SSRN: http://ssrn.com/abstract=982674.

BABbel, D., AND C. MerRIL (2006): "Rational Decumulation," Wharton Financial Institutions Center Working Paper No. 06-14.

Berkowitz, M., AND J. QIU (2006): "A Further Look at Household Portfolio Choice and Health Status," Journal of Banking \& Finance, 30(4), 1201-1217.

Bound, J., T. STINEBRICKNER, AND T. WAIDMAnN (2010): "Health, Economic Resources and the Work Decisions of Older Men,” Journal of Econometrics, 156, 106-129.

Bourguignon, F., M. Browning, And P.-A. Chiappori (2009): "Efficient Intra-Household Allocations and Distribution Factors: Implications and Identification," Review of Economic Studies, 76(2), 503-528.

Brandt, M., A. Goyal, P. Santa-Clara, and J. Stroud (2005): "A Simulation Approach to Dynamic Portfolio Choice with an Application to Learning About Return Predictability," Review of Financial Studies, 18(3), 831-873.

Brook, R., J. Ware, W. Rogers, E. Keeler, A. Davies, G. Donald, Cathy.A. Goldberg, K. Lohr, P. Masthay, and J. Newhouse (1983): “Does Free Care Improve Adults' Health? Results From a Randomized Controlled Trial," New England Journal of Medicine, 309(23), 1426-1434.

Brown, J. (2001): "Private Pensions, Mortality Risk, and the Decisions to Annuitize," Journal of Public Economics, 82(1), 29-62.

- (2007): "Rational and Behavioral Perspectives on the Role of Annuities in Retirement Planning," NBER Working paper No. 13537.

Brown, J., ANd A. Finkelstein (2007): "Why Is the Market for Long-Term Care Insurance So Small?," Journal of Public Economics, 91(10), 1967-1991.

- (2008): "The Interaction of Public and Private Insurance: Medicaid and the Long-Term Care Insurance Market," American Economic Review, 98(3), 1083-1102.

- (2009): "The Private Market for Long-Term Care Insurance in the United States: A Review of the Evidence," Journal of Risk and Insurance, 76(1), 5-29. 
Brown, J., J. Kling, S. Mullainathan, and M. Wrobel (2008): "Why Don't People Insure LateLife Consumption? A Framing Explanation of the Under-Annuitization Puzzle," American Economic Review, 98(2), 304:309.

Bütler, M., K. Peijnenburg, and S. Staubli (2009): "Do Means Tested Benefits Reduce the Demand for Annuities? Evidence from Switzerland," Working paper, University of St.Gallen.

Carroll, C. (2006): "The Method of Endogenous Gridpoints for Solving Dynamic Stochastic Optimization Problems," Economics Letters, 91(3), 312-320.

Chai, J., W. Horneff, R. Maurer, and O. Mitchell (2009): "Extending Life Cycle Models of Optimal Portfolio Choice: Integrating Flexible Work, Endogenous Retirement, and Investment Decisions with Lifetime Payouts," NBER Working Paper No. 15079.

Cherchye, L., B. De Rock, and F. Vermeulen (2010): “The Revealed Preference Approach to Collective Consumption Behavior: Nonparametric Testing and Sharing Rule Recovery," Forthcoming, Review of Economic Studies.

Davidoff, T. (2010): “Home Equity Commitment and Long-Term Care Insurance Demand," Journal of Public Economics, 94(1-2), 44-49.

DAVIdoff, T., J. BRown, And P. DiAmond (2005): “Annuities and Individual Welfare," American Economic Review, 95(5), 1573-1590.

Davidoff, T., AND G. Welke (2007): "Selection and Moral Hazard in the Reverse Mortgage Market," Working Paper, Haas School of Business, UC Berkeley.

DE NARDI, M. (2004): “Wealth Inequality and Intergenerational Links," Review of Economic Studies, 71(3), 743-768.

De Nardi, M., E. French, And J. Jones (2010a): "Why Do The Elderly Save? The Role of Medical Expenses," Journal of Political Economy, 118(1), 39-75.

De Nardi, M., E. French, And J. B. Jones (2010b): "The Effects of Medicaid and Medicare Reforms on the Elderly's Savings and Medical Expenditures," Working paper, Federal Reserve Bank of Chicago.

Dushi, I., And A. WebB (2004): "Household Annuitization Decisions: Simulations and Empirical Analyses," Journal of Pension Economics and Finance, 3(2), 109-143.

Dynan, K., J. Skinner, And S. Zeldes (2004): “Do the Rich Save More?, Journal of Political Economy, 112(2), 397-444.

EDwARDS, R. (2008): “Health Risk and Portfolio Choice," Journal of Business \& Economics, 26(4), 10791088.

FEInstein, J., AND C. Lin (2006): “Elderly Asset Management,” Working paper, Yale School of Management. 
Finkelstein, A., E. LutTmer, And M. Notowidigdo (2008): "What Good Is Wealth Without Health? The Effect of Health on the Marginal Utility of Consumption," NBER Working Paper No. 14089.

Finkelstein, A., E. F. Luttmer, And M. J. Notowidigdo (2009): “Approaches to Estimating the Health State Dependence of the Utility Function," American Economic Review, 99(2), 116-121.

Finkelstein, A., And R. MCKnight (2008): "What Did Medicare Do? The Initial Impact of Medicare on Mortality and Out of Pocket Medical Spending," Journal of Public Economics, 92(7), 1644-1668.

Fonseca, R., P.-C. Michaud, T. Galama, and A. Kapteyn (2009): “On The Rise of Health Spending and Longevity," IZA Discussion Paper No. 4622.

FrEnCH, E. (2005): "The Effects of Health, Wealth, and Wages on Labour Supply and Retirement Behaviour," Review of Economic Studies, 72(2), 395-427.

French, E., And J. Jones (2004): “On the Distribution and Dynamics of Health Care Costs," Journal of Applied Econometrics, 19(6), 705-721.

Gazzale, R., And L. WAlker (2009): "Behavioral Biases in Annuity Choice: An Experiment," Williams College Economics Department Working Paper Series. Available at SSRN: http://ssrn.com/abstract=1370535.

Horneff, W., R. Maurer, O. Mitchell, and M. Stamos (2009): "Asset Allocation and Location over the Life Cycle with Investment-linked Survival-contingent Payouts," Journal of Banking \& Finance, 33(9), 1688-1699.

Hu, W., AND J. SCOTT (2007): "Behavioral Obstacles in the Annuity Market," Financial Analysts Journal, 63(6), 71-82.

Hugonnier, J., F. Pelgrin, And P. St-Amour (2009): "Health and (other) Asset Holdings," Swiss Finance Institute Research Paper No. 09-18. Available at SSRN: http://ssrn.com/abstract=1417364.

Inkmann, J., P. Lopes, And A. Michaelides (2008): "How Deep is the Annuity Market Participation Puzzle?," Working Paper, available at SSRN: http://ssrn.com/abstract=1099911.

Koijen, R., T. NiJman, and B. Werker (2009): "When Can Life-cycle Investors Benefit from TimeVarying Bond Risk Premia?," forthcoming in The Review of Financial Studies.

KopczuK, W., AND J. Lupton (2007): “To Leave or Not to Leave: The Distribution of Bequest Motives," 74, 74(1), 207-235.

Kopecky, K., And T. Koreshrova (2009): "The Impact of Medical and Nursing Home Expenses and Social Insurance Policies on Savings and Inequality," Working paper, University of Western Ontario.

Kotlikoff, L., ANd A. SpivaK (1981): “The Family as an Incomplete Annuities Market," Journal of Political Economy, 89(21), 372-391. 
LockwOoD, L. (2010): "The Importance of Bequest Motives: Evidence from Long-term Care Insurance and the Pattern of Saving," Working paper, University of Chicago.

Love, D., M. Palumbo, and P. Smith (2008): “The Trajectory of Wealth in Retirement,” FEDS Working Paper No. 2008-13. Available at SSRN: http://ssrn.com/abstract=1055641.

Love, D., And M. PerozeK (2007): "Should the Old Play It Safe? Portfolio Choice with Uncertain Medical Expenses," Working paper, Williams college.

Maurer, R., O. Mitchell, And R. Rogalla (2010): “The Effect of Uncertain Labor Income and Social Security on Life-Cycle Portfolios," NBER Working Paper No. 15682.

Mitchell, O., J. Poterba, M. Warshawsky, and J. Brown (1999): “New Evidence on the Money's Worth of Individual Annuities," American Economic Review, 89(5), 1299-1318.

Murtaugh, C., P. Kemper, and B. Spillman (1995): "Risky Business: Long Term Care Insurance Underwriting," Inquiry, 32(3), 271-284.

Palumbo, M. (1999): "Uncertain Medical Expenses and Precautionary Saving Near the End of the Life Cycle," Review of Economic Studies, 66(2), 395-421.

PANG, G., And M. WARShawsky (2010): "Optimizing the Equity-Bond-Annuity Portfolio in Retirement: The Impact of Uncertain Health Expenses," Insurance: Mathematics and Economics, 46(1), 198-209.

PASHCHENKo, S. (2010): “Accounting for Non-Annuitization,” Working paper, University of Virginia.

Peijnenburg, K., T. Nijman, And B. Werker (2010): "Optimal Annuitization with Incomplete Annuity Markets and Background Risk During Retirement," CentER Discussion Paper, 2010-11. Available at SSRN: http://ssrn.com/abstract=1341674.

Poterba, J., S. Venti, And D. Wise (2010): "Family Status Transitions, Latent Health, and the PostRetirement Evolution of Assets," NBER Working Paper No. 15789.

Rodda, D., C. Herber, and H. Lam (2000): “Evaluation Report of FHA's Home Equity Conversion Mortgage Insurance Demonstration," Prepared for US Department of Housing and Urban Development. Available at http://www.huduser.org/Publications/pdf/hecmrpt.pdf.

Scholz, J., A. Seshadri, and S. Khitatrakun (2006): "Are Americans Saving "Optimally" for Retirement," Journal of Political Economy, 114(4), 607-643.

Seshamani, M., And A. Gray (2004): "Ageing and Health-care Expenditure: The Red Herring Argument Revisited," Health Economics, 13(4), 303-314.

Shang, B., And D. Goldman (2007): "Does Age or Life Expectancy Better Predict Health Care Expenditures?," Health Economics, 17(4), 487-501. 
Sinclair, S., And K. Smetters (2004): "Health Shocks and the Demand for Annuities," Technical Paper Series 2004-9, Congressional Budget Office.

Smith, P., And D. Love (2007): “Does Health Affect Portfolio Choice,” Department of Economics Working Papers 2008-11, Department of Economics, Williams College.

Stevens, R. (2009): “Annuity Decisions with Systematic Longevity Risk,” Working paper, Tilburg University.

Turra, C., And O. Mitchell (2008): The Impact of Health Status and Out-of-Pocket Medical Expenditures on Annuity Valuation chap. in John Ameriks and Olivia S. Mitchell, editors, Recalibrating Retirement Spending and Saving, pp. 227-250. Oxford University Press.

Venti, S. F., AND D. A. WISE (2000): “Ageing and Housing Equity,” NBER Working Paper No. 7882.

Viscusi, W. K., And W. N. Evans (1990): "Utility Functions That Depend on Health Status: Estimates and Economic Implications," American Economic Review, 80(3), 353-374.

Weaver, F., S. Stearns, E. Norton, and W. Spector (2009): "Proximity to Death and Participation in the Long-Term Care Market," Health Economics, 18(8), 867-883.

Werblow, A., S. Felder, And P. Zweifel (2007): "Population Ageing and Health Care Expenditures: A School of "Red Herrings"?," Health Economics, 16(10), 1109-1126.

YAARI, M. (1965): “Uncertain Lifetime, Life Insurance and the Theory of the Consumer," Review of Economic Studies, 32(2), 137-150.

YANG, F. (2009): “Consumption over the Life Cycle: How Different is Housing?," Review of Economic Dynamics, 12(3), 423-443.

Yogo, M. (2009): "Portfolio Choice in Retirement: Health Risk and the Demand for Annuities, Housing and Risky Assets,” NBER Working Paper No. 15307.

\section{A Numerical method for solving the life cycle problem}

Due to the richness and complexity of this model it cannot be solved analytically, so we employ numerical techniques. We follow Brandt, Goyal, Santa-Clara, and Stroud (2005) and Carroll (2006) with several extensions by Koijen, Nijman, and Werker (2009). Brandt, Goyal, Santa-Clara, and Stroud (2005) adopt a simulation-based method which can deal with many exogenous state variables. In our case $X_{t}=$ $\left(R_{t}^{f}, \pi_{t}, h_{t}\right)$ is the relevant exogenous state variable. Wealth acts as an endogenous state variable. For this reason, following Carroll (2006), we specify a grid for wealth after (annuity) income, expenses due to background risk, and consumption. As a result, we do not need numerical rootfinding to find the optimal consumption decision. 
The optimization problem is solved via dynamic programming and we proceed backwards to find the optimal investment and consumption strategy. In the last period, the individual consumes all wealth available. The value function at time T equals:

$$
J_{T}\left(W_{T}, R_{T}^{f}, \pi_{T}, h_{t}\right)=\frac{W_{T}^{1-\gamma}}{1-\gamma}
$$

The value function satisfies the Bellman equation at all other points in time,

$$
V_{t}\left(W_{t}, R_{t}^{f}, \pi_{t}, h_{t}\right)=\max _{w_{t}, C_{t}}\left(\frac{C_{t}^{1-\gamma}}{1-\gamma}+\beta p_{t+1} E_{t}\left(V_{t+1}\left(W_{t+1}, R_{t+1}^{f}, \pi_{t+1}, h_{t+1}\right)\right)\right) .
$$

In each period we find the optimal asset weights by setting the first order condition equal to zero

$$
E_{t}\left(C_{t+1}^{*-\gamma}\left(R_{t+1}-R_{t}^{f}\right) / \Pi_{t+1}\right)=0
$$

where $C_{t+1}^{*}$ denotes the optimal real consumption level. Because we solve the optimization problem via backwards recursion, we know $C_{t+1}^{*}$ at time $t+1$. Furthermore, we simulate the exogenous state variables for $\mathrm{N}$ trajectories and $\mathrm{T}$ time periods hence we can calculate the realizations of the Euler conditions, $C_{t+1}^{*-\gamma}\left(R_{t+1}-R_{t}^{f}\right) / \Pi_{t+1}$. We regress these realizations on a polynomial expansion in the state variables to obtain an approximation of the conditional expectation of the Euler condition

$$
E\left(C_{t+1}^{*-\gamma}\left(R_{t+1}-R_{t}^{f}\right) / \Pi_{t+1}\right) \simeq \tilde{X}_{p}^{\prime} \theta_{h}
$$

In addition we employ a further extension, introduced in Koijen, Nijman, and Werker (2009). They found that the regression coefficients $\theta_{h}$ are smooth functions of the asset weights and, consequently, we approximate the regression coefficients $\theta_{h}$ by projecting them further on polynomial expansion in the asset weights:

$$
\theta_{h}^{\prime} \simeq g(w) \psi
$$

The Euler condition must be set to zero to find the optimal asset weights:

$$
\tilde{X}_{p}^{\prime} \psi g(w)^{\prime}=0
$$




\section{B Comparison rule of thumb and life cycle model: optimal annuity demand}

Table 2: Comparison rule of thumb and full model for the health cost models.

In this table we report the welfare costs from using the rule of thumb instead of the full life cycle. Naturally, the main input in the rule of thumb, the health costs in the first five years of retirement differs in the four models. The health costs are $\$ 13,000$, $\$ 42,000, \$ 44,000$, and $\$ 10,000$ for respectively the exponential, piecewise constant, hump-shaped, and linear model. Throughout, a minimum consumption level of $C_{\min }=7000$ is used. The survival probabilities are different in all four models, hence the annuity factor, life expectancy, and the age that individuals reach with a $35 \%$ probability also differs.

\begin{tabular}{c|ccc|ccc}
\hline \hline & \multicolumn{2}{|c|}{ piecewise constant: $\mathrm{H}=42,000$} & \multicolumn{3}{c}{ exponential: $\mathrm{H}=13,000$} \\
\hline total wealth & welfare loss & full model & rule of thumb & welfare loss & full model & rule of thumb \\
\hline 200,000 & 1.7 & 76 & 100 & 0 & 100 & 100 \\
250,000 & 3.3 & 72 & 100 & 0 & 100 & 100 \\
300,000 & 3.4 & 68 & 100 & 0 & 100 & 100 \\
350,000 & 3.4 & 66 & 100 & 0 & 100 & 100 \\
400,000 & 0.2 & 63 & 53 & 0 & 100 & 100 \\
450,000 & 0.1 & 61 & 60 & 0 & 100 & 100 \\
500,000 & 0.2 & 58 & 66 & 0 & 100 & 100 \\
550,000 & 1.1 & 57 & 70 & 0 & 100 & 100 \\
600,000 & 2.7 & 56 & 74 & 0 & 100 & 100 \\
650,000 & 2.7 & 54 & 78 & 0 & 100 & 100 \\
700,000 & 3.0 & 53 & 81 & 0 & 100 & 100 \\
750,000 & 4.5 & 53 & 83 & 0 & 100 & 100 \\
\hline \hline & \multicolumn{7}{c|}{ linear: H=10,000 } & & hump-shaped: H=44,000 \\
\hline total wealth & welfare loss & full model & rule of thumb & welfare loss & full model & rule of thumb \\
\hline 200,000 & 0 & 100 & 100 & 1.2 & 75 & 100 \\
250,000 & 0 & 100 & 100 & 1.9 & 72 & 100 \\
300,000 & 0 & 100 & 100 & 2.6 & 69 & 100 \\
350,000 & 0 & 100 & 100 & 3.1 & 66 & 100 \\
400,000 & 0 & 100 & 100 & 0.3 & 63 & 50 \\
450,000 & 0 & 100 & 100 & 0 & 60 & 56 \\
500,000 & 0 & 100 & 100 & 0.1 & 58 & 62 \\
550,000 & 0 & 100 & 100 & 0.3 & 57 & 67 \\
600,000 & 0 & 100 & 100 & 0.9 & 56 & 71 \\
650,000 & 0 & 100 & 100 & 1.4 & 55 & 75 \\
700,000 & 0 & 100 & 100 & 2.4 & 54 & 78 \\
750,000 & 0 & 100 & 100 & 2.3 & 53 & 81 \\
\hline \hline
\end{tabular}

